\title{
Validação de um opinário sobre aquecimento global
}

\author{
Alexandre Luis Junges ${ }^{\star}$, Fernando Lang da Silveira ${ }^{\star \star}$, Neusa Teresinha Massoni ${ }^{\star \star \star}$
}

\section{Resumo}

O aquecimento global tem sido reconhecido por especialistas como um tema prioritário da agenda da educação ambiental para o século 21. Cientistas têm alertado sobre a necessidade de lidar com o desafio das mudanças climáticas causadas pelas emissões antropogênicas de gases de efeito estufa. Apesar disso, a percepção sobre o tema entre o público leigo é difusa. No contexto internacional, estudos têm revelado que um número considerável de cidadãos leigos não acredita em aquecimento global antropogênico, ou consideram que não existe consenso científico a respeito dessa matéria. Neste sentido, tendo em vista a importância do tema e as diferenças de opinião entre o leigo e o especialista, averiguadas em contextos internacionais, torna-se relevante desenvolver pesquisas similares no contexto brasileiro local. O presente trabalho descreve o desenvolvimento de um instrumento de medida capaz de avaliar a opinião de cidadãos e alunos em diferentes níveis de ensino, no contexto brasileiro, sobre a temática do aquecimento global. Para tanto, são descritos os passos de desenvolvimento, aplicação e validação de um opinário sobre aquecimento global. O opinário, composto de doze itens, foi disponibilizado online em redes sociais e listas de e-mails através do software LimeSurvey, obtendo-se um total de 1084 respostas. Descrevemos o processo de validação de conteúdo e de construto do opinário que culminou em um instrumento de medida apropriado para quantificar o grau de concordância ou discordância de sujeitos frente ao construto "aquecimento global antropogênico". Por fim, são discutidas possíveis correlações entre as variáveis de caracterização da amostra de sujeitos e a crença no aquecimento global antropogênico.

Palavras-chave: aquecimento global; mudanças climáticas; pesquisa de opinião; validação de opinário.

\footnotetext{
- Universidade Federal do Rio Grande do Sul - Departamento Interdisciplinar - Campus Litoral Norte, Tramandaí - RS. Brasil. E-mail: alexandre.junges@ufrgs.br

* Universidade Federal do Rio Grande do Sul - Instituto de Física, Porto Alegre - RS. Brasil. E-mail: lang@if.ufrgs.br

*** Universidade Federal do Rio Grande do Sul - Instituto de Física, Porto Alegre - RS. Brasil. E-mail: neusa. massoni@if.ufrgs.br
}

Recebido em: 24/06/2020 - Aceito em: 25/01/2021

https://doi.org/ 10.5335/rbecm.v4i1.11233

http://creativecommons.org/licenses/by-nc-nd/4.0 


\section{Introdução}

A temática do aquecimento global e mudanças climáticas ${ }^{1}$ tem sido uma das mais debatidas no meio científico e social e vem sendo reconhecida como prioritária da agenda da educação ambiental para o século 21 (IALEI, 2009; JACOBI et al., 2011). Historicamente, a comunidade científica tem debatido as causas e consequências das mudanças climáticas por mais de um século (WEART, 2008; FLEMING, 1998). A partir da criação do IPCC (Painel Intergovernamental sobre Mudanças Climáticas) diversos relatórios científicos têm, constantemente, avaliado e reavaliado essa problemática (IPCC, 2013) ${ }^{2}$. Historiadores e outros pesquisadores ocupados com o tema têm argumentado que, nas primeiras décadas do século 21 , um consenso científico tem sido formado em torno da existência de um aquecimento global causado, principalmente, pelas emissões antropogênicas de gases de efeito estufa (WEART, 2008; ORESKES, 2004). Trabalhos que avaliaram o nível de consenso entre especialistas concluíram que mais de $95 \%$ dos cientistas que publicam ativamente em revistas da área de estudo do clima, concordam sobre a existência de um aquecimento global causado pela ação humana (ORESKES, 2004; ANDEREGG et al., 2010; DORAN; ZIMMERMAN, 2009; COOK et al., 2013) ${ }^{3}$.

Contudo, se a partir desses trabalhos podemos considerar que existe um consenso científico sobre as causas do aquecimento global, o mesmo não acontece entre o público leigo. No contexto americano, por exemplo, estudos têm revelado que um número considerável de não especialistas (leigos) não acredita em aquecimento global antropogênico, ou consideram que não exista consenso científico a respeito dessa matéria. Num estudo conduzido com uma amostra de 2030 adultos americanos, Leiserowitz e Smith (2010) concluíram que apenas 50\% do público admite que o aquecimento global tenha como causa principal as atividades humanas e somente $39 \%$ que existe um forte consenso entre especialistas a esse respeito. Em outro estudo envolvendo uma amostra de 1500 professores de ciências da educação básica, Plutzer et al. (2016) concluíram que, mesmo entre aqueles professores que consideram que aquecimento global é de origem antrópica, apenas 50\% destes consideram que existe uma forte concordância dentro da comunidade científica sobre a causa antropogênica do aquecimento global.

Nesse sentido, tendo em vista a importância e centralidade do tema para 0 século 21 e as diferenças de opinião entre o leigo e o especialista, averiguadas em 
contextos internacionais, torna-se relevante desenvolver pesquisas similares no contexto brasileiro local. Essa relevância se estende especialmente para o campo da educação. Desde muito tempo, teóricos do campo da educação científica têm reconhecido a importância de averiguar as crenças e concepções prévias dos alunos para poder melhor planejar as ações de ensino (DRIVER, 1989; MOREIRA, 2011). Dessa forma, na medida em que a temática do aquecimento global é uma questão sociocientífica complexa que envolve diferentes opiniões e posições entre sujeitos (LOMBARDI; SINATRA, 2012), inclusive, despertando diferentes reações e emoções que dificultam o seu ensino e aprendizagem (LOMBARDI; SINATRA, 2013), torna-se relevante que o professor disponha de instrumentos confiáveis que permitam uma avaliação prévia das crenças e posições de determinado grupo de alunos, seja da escola de nível médio ou universitário, afim de melhor planejar a sua abordagem de ensino sobre o tema.

O presente trabalho tem por objetivo apresentar e validar um instrumento de medida capaz de avaliar a opinião de cidadãos e alunos, em diferentes níveis de ensino, no contexto brasileiro, sobre a temática do aquecimento global. Para tanto, são descritos os passos de desenvolvimento, aplicação e validação de um opinário sobre aquecimento global, composto de dez itens do tipo Likert e dois de múltipla escolha.

Os resultados descritos foram obtidos com a aplicação do opinário anônimo a uma amostra casual de 1084 respondentes para averiguar o posicionamento dos sujeitos frente ao construto Aquecimento Global Antropogênico (AGA). As respostas foram obtidas disponibilizando o opinário online em redes sociais e listas de e-mails através do software LimeSurvey entre dezembro de 2018 e março de 2019. Cabe notar que os blogs e redes sociais em que o opinário foi disponibilizado online são, geralmente, frequentados por um público interessado por questões científicas. Dessa forma, tal procedimento resultou em uma amostra casual não aleatória e, portanto, não representativa da população brasileira em geral, de modo que os resultados da pesquisa de opinião aqui expressos limitam-se à amostra dos 1084 sujeitos.

Contudo, como já destacado, a principal contribuição do presente trabalho para o campo da pesquisa em ensino de ciências reside no processo de validação de conteúdo e de construto do opinário. Esse processo de validação, com a análise de consistência interna do opinário, identificou o construto Aquecimento Global Antropogênico (AGA), resultando em um instrumento de medida confiável e passível 
de ser empregado e adaptado seja na sala de aula ou em outras pesquisas futuras que pretendam investigar o posicionamento de uma amostra de respondentes sobre o tema.

Na próxima seção iniciaremos com uma breve revisão (não sistemática) da literatura sobre trabalhos que fizeram uso de questionários para averiguar concepções e opiniões de sujeitos sobre aquecimento global e mudanças climáticas. A seguir é feita a apresentação do opinário sobre aquecimento global junto com a discussão do processo da validação de conteúdo e de construto, especialmente, com o detalhamento da análise de consistência interna. Como veremos, este procedimento estatístico envolverá dois momentos. Num primeiro momento será feita a análise de consistência interna dos dez itens do tipo Likert. Em seguida, é descrito um procedimento estatístico para inclusão dos dois itens de múltipla escolha na análise de consistência interna, compondo, assim, uma escala de doze itens indicadora da opinião sobre aquecimento global antropogênico.

Passamos, então, para a caracterização da amostra dos 1084 respondentes de acordo com informações básicas como idade, sexo, grau de escolaridade, etc. Tal caracterização é apresentada na forma de gráficos de barra com as distribuições de frequência para cada uma das variáveis. Por fim, apresentamos uma seção dedicada à discussão sobre a correlação entre as variáveis de caracterização dos respondentes e o escore obtido nos doze itens da escala de opinião sobre aquecimento global. Faremos isso a partir do cálculo do coeficiente de correlação Eta (WHERRY, 1984) entre a variável nominal de caracterização do respondente e o escore obtido na escala de opinião, apresentando algumas observações sobre as correlações obtidas. Finalmente, tecemos algumas considerações sobre a opinião da amostra de respondentes frente ao aquecimento global e frente ao consenso científico.

\section{Revisão da literatura}

O emprego de questionários tem servido como importante ferramenta para diagnosticar crenças, concepções e atitudes de sujeitos em diferentes contextos, inclusive educacional. No campo da educação científica, a temática das concepções e atitudes de professores e alunos sobre o meio ambiente e temas correlatos constitui um campo de pesquisa muito desenvolvido. Pesquisas têm revelado que alunos, e mesmo professores formados ou em formação possuem crenças, concep- 
ções e modelos mentais sobre o meio ambiente que nem sempre correspondem ao entendimento científico sobre determinado tema. Relacionado ao tema do aquecimento global e mudanças climáticas, diversos artigos têm revelado que, embora a maioria das pessoas educadas (estudantes de nível médio e graduação) já tenha tomado conhecimento, através da mídia ou no ambiente escolar, sobre a temática, poucos possuem uma compreensão conceitual adequada a esse respeito (ARSLAN; CIGDEMOGLU; MOSELEY, 2012; LAMBERT; LINDGREN; BLEICHER, 2012; RATINEN, 2013; NIEBERT; GROPENGIESSER, 2014; REINFRIED; TEMPELMAN, 2014; DAWSON, 2015).

Tais trabalhos têm evidenciado que muitos alunos não sabem identificar os principais gases estufa, (dióxido de carbono, vapor d'água, metano, óxido nitroso, etc), bem como não compreendem os mecanismos de absorção da radiação infravermelho por parte das moléculas dos gases estufa (RATINEN, 2013; DAWSON, 2015). Apresentam a concepção equivocada de que os gases de efeito estufa causam o buraco na camada de ozônio (RATINEN, 2013; DAWSON, 2015), ou ainda, de que o buraco na camada de ozônio é o responsável pelo aquecimento global (ARSLAN; CIGDEMOGLU; MOSELEY, 2012; LAMBERT; LINDGREN; BLEICHER, 2012). Muitos alunos explicam o efeito estufa através da ideia de que o aquecimento é devido a uma maior entrada de radiação. Neste caso, o responsável pelo aquecimento é ou o Sol (aumento da radiação solar) ou o buraco do ozônio (maior entrada de radiação) (REINFRIED; TEMPELMAN, 2014). Outros consideram que o efeito estufa é um fenômeno totalmente prejudicial para a humanidade, não reconhecendo que este é um fenômeno natural que faz com que a Terra tenha temperaturas propícias ao desenvolvimento da vida (ARSLAN; CIGDEMOGLU; MOSELEY, 2012; RATINEN, 2013). Ainda há aqueles que não distinguem adequadamente entre tempo meteorológico e clima (DAWSON, 2015; LOMBARDI; SINATRA, 2012).

De maneira geral, tais trabalhos adotam diferentes referenciais teóricos e metodológicos para averiguar concepções ou atitudes dos alunos e professores. Abordagens qualitativas frequentemente recorrem a entrevistas, gravações de aulas, mapas conceituais e intervenções com promoção de discussões em grupo (REINFRIED; TEMPELMAN, 2014; NIEBERT; GROPENGIESSER, 2014). Abordagens quantitativas utilizam-se, em geral, de testes de múltipla escolha e escalas de atitude do tipo Likert para diagnosticar as concepções ou posicionamentos dos respondentes frente ao aquecimento global e às mudanças climáticas (ARSLAN; 
CIGDEMOGLU; MOSELEY, 2012; LAMBERT; LINDGREN; BLEICHER, 2012; LOMBARDI; SINATRA, 2012). Outros trabalhos adotam metodologias mistas com uso de questionários abertos e fechados (DAWSON, 2015; RATINEN, 2013).

Apesar de não fornecer o mesmo grau de aprofundamento e detalhamento do que a abordagem qualitativa, o emprego de abordagens quantitativas têm a vantagem de serem de fácil administração e fornecer um diagnóstico rápido sobre o entendimento ou posição dos alunos sobre determinado tema científico (GUREL; ERYILMAZ; McDERMOTT, 2015). No contexto internacional, diversos trabalhos têm desenvolvido estudos de validação de instrumentos fidedignos especificamente voltados para o tema das mudanças climáticas.

Como exemplos de estudos na área de ensino que envolvem validação de escalas de atitude ou opinião do tipo Likert, no contexto da temática do aquecimento global e mudanças climáticas, podemos destacar Herman, Feldman e Vernaza-Hernandez (2017), Christensen e Knezek (2015), Lombardi, Sinatra e Nussbaum (2013) e Lombardi e Sinatra (2012). Herman, Feldman e Vernaza-Hernandez (2017) utilizaram um amplo questionário incluindo vinte itens do tipo Likert para avaliar a percepção de um total de 220 professores do ensino médio sobre as causas das mudanças climáticas e sobre a natureza da ciência climática. Lombardi e Sinatra (2012) estudaram as concepções de 83 alunos universitários que frequentavam cursos de Geografia Física e cursos introdutórios sobre aquecimento global, empregando questionários com questões de múltipla escolha fechadas e escala Likert. A escala Likert desenvolvida, denominada Plausibility Perceptions Measure, é composta de oito itens destinada a medir a percepção de plausibilidade dos respondentes sobre as causas antropogênicas das mudanças climáticas. Já Lombardi, Sinatra e Nussbaum (2013) empregaram uma escala Likert de 27 itens aplicada em 169 alunos da escola básica para medir o posicionamento de participantes sobre a influência humana nas mudanças climáticas. Por sua vez, Christensen e Knezek (2015) descrevem em detalhe o processo de validação do instrumento The climate change attitude survey composto de 15 itens do tipo Likert para averiguar crenças (nove itens) e intenções (seis itens) de sujeitos sobre as mudanças climáticas. A validação ocorreu a partir da aplicação do instrumento a uma amostra de 1576 alunos da educação básica americana.

No contexto nacional, parece haver uma necessidade de mais pesquisa no desenvolvimento e validação de instrumentos especificamente voltados para a temática 
climática. Realizando uma breve busca online, através do site Google Acadêmico, não foram encontrados estudos de validação de testes de atitudes sobre aquecimento global ou sobre mudanças climáticas publicados em revistas acadêmicas da área de ensino de ciências. Mesmo que estudos similares, não mapeados aqui, possam existir no contexto nacional, considera-se importante que mais pesquisas envolvendo a construção e validação de testes de atitudes, bem como testes de múltipla escolha, sejam desenvolvidas sobre a temática do aquecimento global. Como já apontado, o presente trabalho visa contribuir no atendimento a essa demanda de pesquisa.

\section{opinário sobre aquecimento global}

O opinário, aplicado no presente estudo, foi desenvolvido a partir de alguns dos trabalhos da área de ensino de ciências apresentados na revisão da literatura que realizaram levantamentos de opiniões e concepções sobre a temática do aquecimento global. Entre estes, destacam-se Arslan, Cigdemoglu e Moseley (2012); Lambert, Lindgren e Bleicher (2012), Lombardi, Sinatra e Nussbaum (2013) e Lombardi e Sinatra (2012). Além desses trabalhos da área de ensino, alguns itens do opinário foram formulados tomando por base a extensa lista de questões contidas no questionário de Leiserowitz e Smith (2010). Visando o rigor conceitual na construção dos itens também foram consultados livros acadêmicos e relatórios que discutem a ciência do aquecimento global e que formaram a base das asserções de conhecimento consideradas na elaboração do opinário (GOODY; WALKER, 1996; CHRISTOPHERSON, 2012; BARRY; CHORLEY, 2013; IPCC, 2013).

Após a construção de uma primeira versão do opinário, passou-se para o processo de validação de conteúdo ${ }^{4}$ onde contamos com a colaboração de três professores pesquisadores da área de Ensino de Física que fizeram a revisão detalhada das questões (itens) do opinário. A partir das sugestões fornecidas pelos revisores, o opinário foi retificado e reformulado, reduzindo-se o número de itens e buscando remover ambiguidades.

O opinário está dividido em três partes. A primeira parte trata de informações básicas sobre o respondente, sem, no entanto, solicitar a identificação do respondente. Tais informações são solicitadas na seguinte ordem: idade, sexo, nacionalidade, unidade da federação onde mora, grau de escolaridade, área de formação. Pergunta-se, também, pelo nível de informação sobre o tema que o respondente se 
auto atribui: muito informado, informado, pouco informado, nunca me informei a respeito. Por fim, pergunta-se sobre as fontes de informação que o respondente consulta para se informar sobre o tema, apresentando as seguintes opções de escolha: Internet (youtube, blogs e redes sociais); Televisão, Rádio e Jornais; Websites do Governo e Centros de Pesquisa (Nasa, Inpe, etc); Livros e/ou Revistas Científicas; Escola e/ou Universidade. Para cada uma dessas alternativas é então solicitada uma resposta que reflita a frequência de consulta, conforme: Com frequência, Às vezes, Raramente, Nunca.

A segunda parte do opinário envolve dez itens que constituem uma escala de Likert (LIKERT, 1986). Essa parte do opinário visa averiguar a opinião/crença do respondente frente às asserções que: afirmam ou negam a existência do aquecimento global, afirmam a influência humana no aquecimento global, enfatizam a ação de fatores naturais no aquecimento global, tratam da controvérsia / consenso científico sobre o tema e afirmam ou negam a relevância e urgência ambiental do tema para o Século 21. Nesse sentido, tais itens buscam quantificar, através de afirmativas diversificadas, o grau de concordância/discordância do respondente frente à temática do aquecimento global antropogênico, como será detalhado na análise de consistência interna e validade de construto, apresentada na próxima seção. A Tabela 1 apresenta os dez itens do tipo Likert do opinário. Em cada um dos dez itens o respondente expressa seu grau de concordância ou discordância em uma gradação de onze pontos que deve acompanhar cada questão, onde: $0=$ Discordo Fortemente; $5=$ Não Concordo nem Discordo; $10=$ Concordo Fortemente.

Finalmente, na terceira parte do opinário temos dois itens do tipo fechado, de múltipla escolha, que tratam da dinâmica do sistema climático e do estatuto epistemológico da ciência climática (Tabela 2). Ou seja, visam investigar a percepção do respondente frente à questão da estabilidade e da dinâmica do sistema climático da Terra, bem como a percepção sobre a ciência do aquecimento global e seu desenvolvimento histórico. 
Tabela 1: Os dez itens do tipo Likert do opinário.

Opinário sobre Aquecimento Global - Itens do tipo Likert

1. As ações humanas estão levando a um aumento significativo das concentrações de gases de efeito estufa na atmosfera.

$\begin{array}{lllllllllllll}\text { Discordo Fortemente } & 0 & 1 & 2 & 3 & 4 & 5 & 6 & 7 & 8 & 9 & 10 & \text { Concordo Fortemente }\end{array}$

2. O aquecimento global está ocorrendo. Nas últimas décadas tem-se observado que a atmosfera e os oceanos estão aquecendo, que a cobertura de gelo e neve tem diminuído e que o nível do mar tem aumentado.

$\begin{array}{lllllllllllll}\text { Discordo Fortemente } & 0 & 1 & 2 & 3 & 4 & 5 & 6 & 7 & 8 & 9 & 10 & \text { Concordo Fortemente }\end{array}$

3. Não existe aquecimento global. Não há evidências científicas que indiquem que a Terra esteja aquecendo.

$\begin{array}{lllllllllllll}\text { Discordo Fortemente } & 0 & 1 & 2 & 3 & 4 & 5 & 6 & 7 & 8 & 9 & 10 & \text { Concordo Fortemente }\end{array}$

4. A ação humana é muito pequena comparada com as forças naturais. Logo, as atividades humanas têm pouco efeito sobre o clima.

$\begin{array}{lllllllllllll}\text { Discordo Fortemente } & 0 & 1 & 2 & 3 & 4 & 5 & 6 & 7 & 8 & 9 & 10 & \text { Concordo Fortemente }\end{array}$

5. É muito provável que as emissões humanas de gases de efeito estufa sejam o principal fator responsável pelo aquecimento global.

$\begin{array}{lllllllllllll}\text { Discordo Fortemente } & 0 & 1 & 2 & 3 & 4 & 5 & 6 & 7 & 8 & 9 & 10 & \text { Concordo Fortemente }\end{array}$

6. No passado a Terra apresentou diversos ciclos naturais de aquecimento e resfriamento. Assim, muito provavelmente as mudanças climáticas atuais sejam devidas a um ciclo natural.

Discordo Fortemente $\quad \begin{array}{lllllllllllll}0 & 1 & 2 & 3 & 4 & 5 & 6 & 7 & 8 & 9 & 10 & \text { Concordo Fortemente }\end{array}$

7. A existência de um aquecimento global causado pela ação humana ainda é matéria de ampla disputa na comunidade científica, não havendo consenso científico a respeito.

$\begin{array}{lllllllllllll}\text { Discordo Fortemente } & 0 & 1 & 2 & 3 & 4 & 5 & 6 & 7 & 8 & 9 & 10 & \text { Concordo Fortemente }\end{array}$

8. O aquecimento global decorrente da atividade humana é uma farsa criada pelos países ricos para limitar o crescimento econômico de países em desenvolvimento como o Brasil.

$\begin{array}{lllllllllllll}\text { Discordo Fortemente } & 0 & 1 & 2 & 3 & 4 & 5 & 6 & 7 & 8 & 9 & 10 & \text { Concordo Fortemente }\end{array}$

9. O aquecimento global decorrente da atividade humana constitui um dos principais problemas ambientais do século XXI.

$\begin{array}{lllllllllllll}\text { Discordo Fortemente } & 0 & 1 & 2 & 3 & 4 & 5 & 6 & 7 & 8 & 9 & 10 & \text { Concordo Fortemente }\end{array}$

10. Se nada for feito as atividades humanas terão um grande impacto sobre o clima e as futuras gerações.

$\begin{array}{lllllllllllll}\text { Discordo Fortemente } & 0 & 1 & 2 & 3 & 4 & 5 & 6 & 7 & 8 & 9 & 10 & \text { Concordo Fortemente }\end{array}$


Tabela 2: Os dois itens de múltipla escolha do opinário.

\begin{tabular}{l} 
Opinário sobre Aquecimento Global - Itens de Múltipla Escolha \\
\hline 11. Qual das alternativas melhor descreve o comportamento do clima da Terra? \\
(a) O clima da Terra é muito estável; um aquecimento global terá pouco efeito sobre o clima. \\
(b) O clima da Terra é estável dentro de certos limites; se o aquecimento for grande, efeitos imprevisiveis \\
e perigosos surgirāo. \\
(c) O clima da Terra possui um equilibrio delicado; um pequeno aquecimento do planeta pode levar a mudanças \\
abruptas e catastróficas. \\
(d) O clima da Terra muda de forma lenta; um aquecimento global conduzirá a uma mudança gradual do clima. \\
12. Qual das alternativas melhor descreve a pesquisa cientifica sobre aquecimento global? \\
(a) É uma área de pesquisa historicamente consolidada; é consenso entre cientistas que o aquecimento global \\
existe e que é causado pela atividade humana. \\
(b) É uma área de pesquisa complexa com muitas incertezas envolvidas; cientistas ainda não sabem se a atividade \\
humana afeta ou nấo o clima do planeta. \\
(c) É uma área de pesquisa complexa com muitas incertezas envolvidas, contudo, cientistas já sabem que a \\
atividade humana afeta o clima do planeta. \\
(d) É uma área de pesquisa dominada por uma tendência a favor do aquecimento global; cientistas com \\
visóes contrárias săo frequentemente silenciados e impedidos de publicar seus resultados.
\end{tabular}

\section{A análise de consistência interna para os dez itens do tipo Likert}

O estudo de consistência interna do opinário foi realizado com os doze itens em que o respondente pode manifestar seu posicionamento ou opinião frente ao aquecimento global. Como já assinalado, os dez primeiros itens são do tipo Likert e expressam afirmações sobre o aquecimento global, os dois itens subsequentes são de múltipla escolha. A análise estatística foi realizada através do software IBM SPSS Statistics 17.0.

A primeira etapa da análise de consistência interna consiste na testagem da unidimensionalidade dos dez itens do tipo Likert, ou seja, verificar se os dez itens constituem de fato uma escala de atitude ou opinião, conforme o método de medida proposto por Likert (1986). A testagem da unidimensionalidade da opinião expressa pelos dez itens foi realizada através de uma análise fatorial pelo método das componentes principais (SPEARRITT, 1997). Para tanto, foram invertidas previamente as gradações dos itens $3,4,6,7$ e 8 e, desta forma, quanto mais alto o escore em qualquer item, tanto maior é a concordância do respondente com o aquecimento global antropogênico. A fatoração dos dez itens, a partir das respostas de 1084 respondentes, leva a que apenas a primeira componente possua autovalor superior à unidade, conforme representado no diagrama de sedimentação (scree plot) da Figura 1. 
Figura 1: Diagrama de sedimentação (scree plot) das componentes resultantes da fatoração dos dez itens.

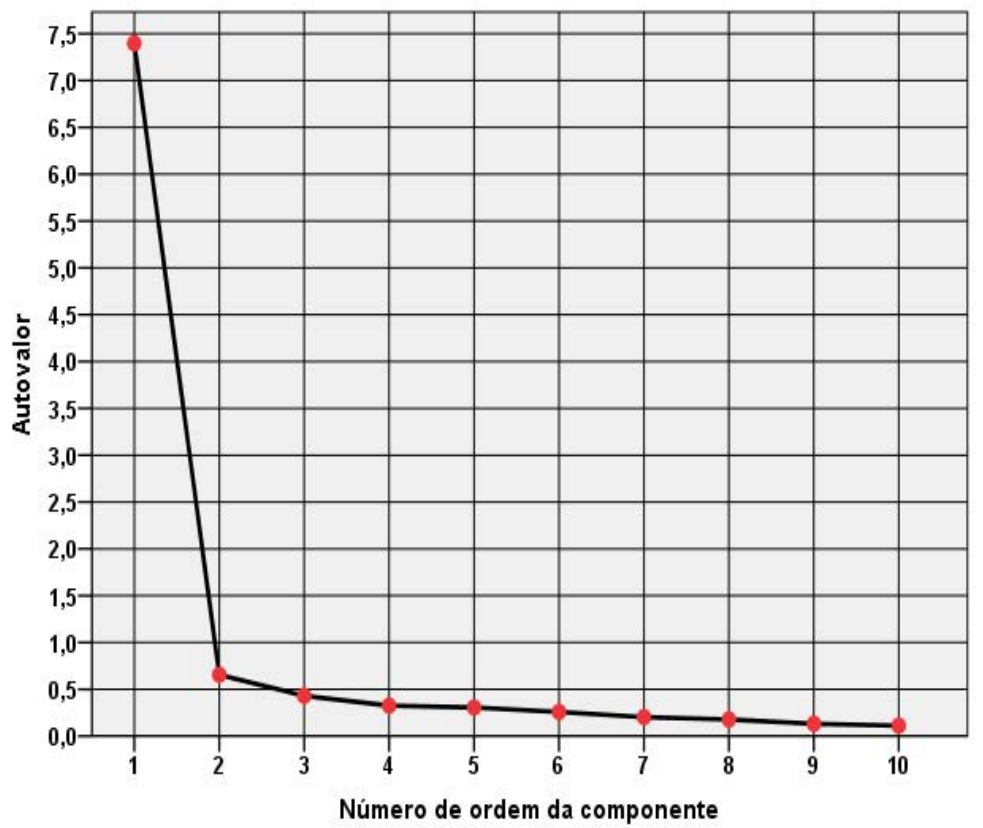

Desta forma, a análise fatorial dos dez itens corrobora a existência de apenas um fator importante (com autovalor superior à unidade), explicando $74 \%$ da variância dos dez itens, verificando empiricamente a unidimensionalidade da opinião relacionada a um único traço latente do instrumento de medida. A partir do autovalor de uma componente, pode-se calcular o coeficiente alfa de Cronbach desta componente (MULAIK, 1972, p.211); neste caso, como o autovalor da primeira componente é 7,40 , o coeficiente alfa resulta em $10 / 9(1-1 / 7,40)=0,96$.

A Tabela 3 apresenta a carga fatorial de cada item na primeira componente, configurando que todos os itens, por possuírem cargas positivas e superiores a 0,60 , podem ser mantidos para compor a escala de medida. A carga fatorial é o coeficiente de correlação de Pearson entre o escore no item e o escore na componente principal. 
Tabela 3: Carga fatorial de cada item na primeira componente principal.

\begin{tabular}{|c|c|}
\hline Item & Carga \\
\hline 1 & $0,91^{*}$ \\
\hline 2 & $0,89^{\star}$ \\
\hline 3 & $0,84^{\star}$ \\
\hline 4 & $0,87^{\star}$ \\
\hline 5 & $0,88^{*}$ \\
\hline 6 & $0,84^{\star}$ \\
\hline 7 & $0,68^{*}$ \\
\hline 8 & $0,83^{*}$ \\
\hline 9 & $0,92^{*}$ \\
\hline 10 & $0,92^{*}$ \\
\hline \multirow{2}{*}{ - nível de significância estatística $<0,001$} \\
\hline
\end{tabular}

Com isso, efetivamos a validação de construto (traço latente) do opinário no que tange aos dez itens do tipo Likert. A análise de consistência, com a obtenção de um valor do coeficiente alfa de Cronbach de 0,96 , permite concluir que o instrumento tem fidedignidade, sendo apropriado para medir o traço latente em questão. Com base na análise de conteúdo dos dez itens, podemos interpretar o traço latente do instrumento como sendo o Aquecimento Global Antropogênico (AGA). Em suma, os dez itens do tipo Likert do opinário compõem uma escala que mede concordância ou discordância do respondente frente ao o construto AGA.

A partir disso, foi criada uma nova variável denominada Escore AGA que expressa a média dos escores dos dez itens Likert. Ou seja, para cada um dos 1084 respondentes é atribuído um escore médio que quantifica sua opinião. Quanto mais alto (próximo de 10) for o escore médio resultante tanto maior é a concordância do sujeito com a existência de um aquecimento global antropogênico. Um valor menor que cinco (5) indica discordância com o AGA e uma média próxima de zero expressa a negação do aquecimento global antropogênico. Com isso, podemos descrever o grau de concordância ou discordância da amostra de respondentes frente ao construto AGA. A Figura 2 apresenta, na forma de histograma, o escore médio nos dez itens para todos os respondentes. 
Figura 2 : Histograma do Escore AGA dos 10 itens para a amostra de 1084 sujeitos.

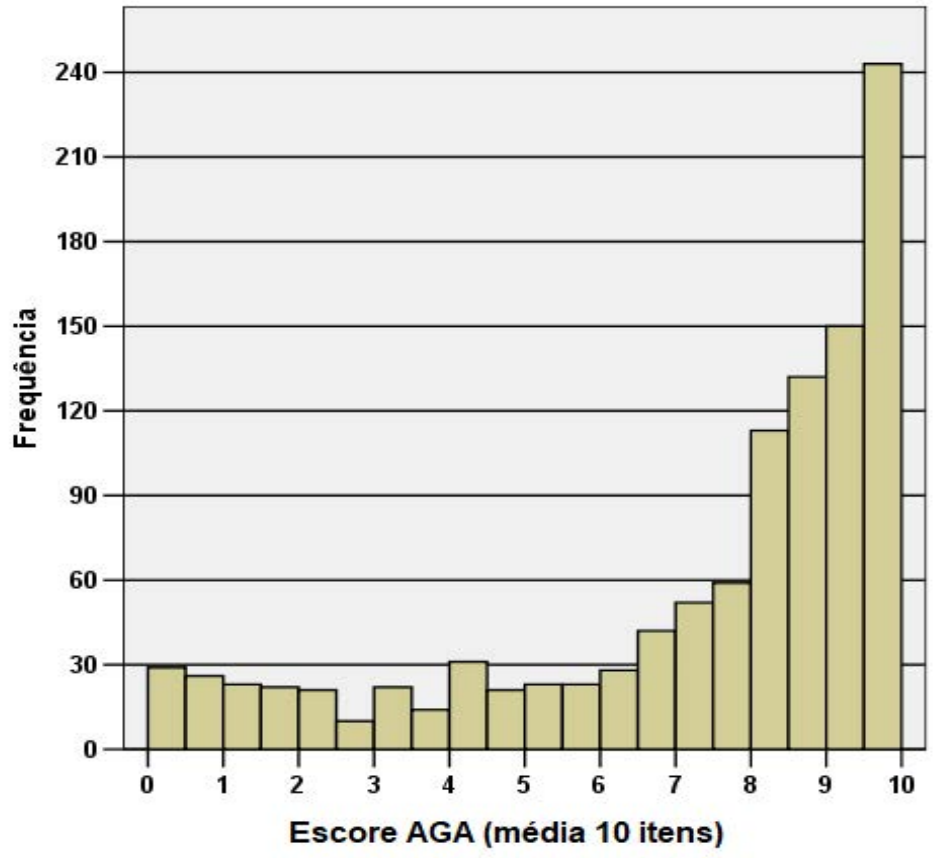

Complementando, a Tabela 4 resume diversas estatísticas do Escore AGA para a amostra de respondentes.

Tabela 4: Estatísticas do Escore AGA obtido dos dez itens.

\begin{tabular}{|c|l|}
\hline \multicolumn{2}{|c|}{ Estatísticas do escore AGA } \\
\hline Média & 7,3 \\
\hline Mediana & 8,0 \\
\hline Moda & 10,0 \\
\hline Desvio padrão & 2,8 \\
\hline Coeficiente alfa de Cronbach & 0,96 \\
\hline
\end{tabular}

\section{Extensão da análise de consistência interna para os doze itens do opinário}

Passaremos agora a estender a análise de consistência interna incluindo os itens 11 e 12, de escolha múltipla, do opinário. Lembrando que nos itens 11 e 12, cada respondente escolhe entre quatro afirmativas aquela que melhor expressa a sua 
opinião. O primeiro passo dessa análise é verificar se os dois itens possuem relação com o Escore AGA. Assim, o procedimento consiste em comparar os escores médios de AGA dos grupos de respondentes de cada uma das alternativas de resposta dos itens 11 e 12. Uma forma de fazê-lo é através do gráfico de barra de erro para 0 Escore AGA das alternativas de resposta (Figuras 3 e 4). Junto ao gráfico também é apresentado o cálculo do coeficiente Eta e o nível de significância estatística (ns). O coeficiente Eta é um coeficiente de correlação entre uma variável nominal e uma variável intervalar (WHERRY, 1983).

Figura 3: Gráfico de barra de erro para o Escore AGA nas quatro alternativas de resposta ao item 11 do opinário.

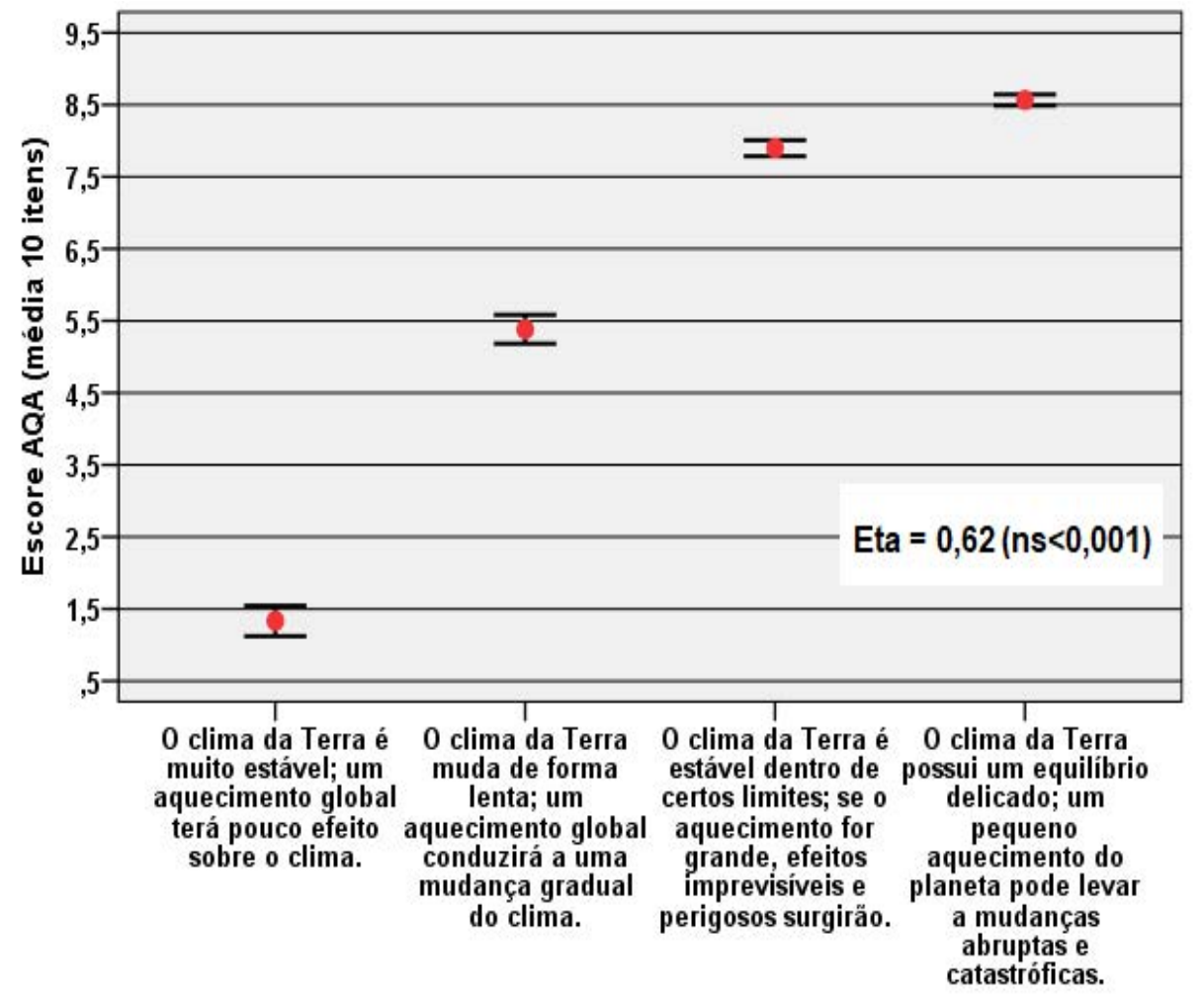

11. Qual das alternativas melhor descreve o comportamento do clima da Terra? 
Figura 4: Gráfico de barra de erro para o Escore AGA nas quatro alternativas de resposta ao item 12 do opinário.

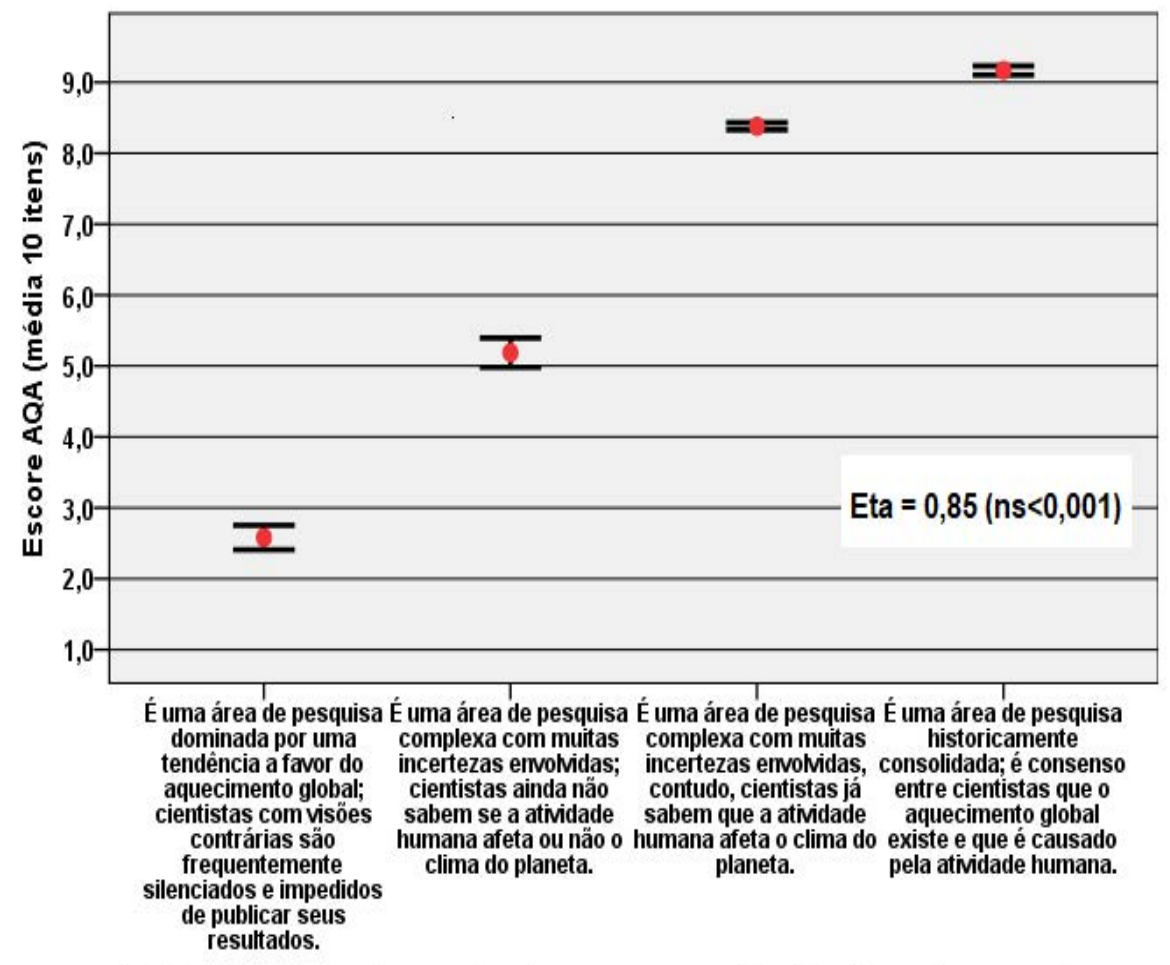

12. Qual das alternativas melhor descreve a pesquisa cientifica sobre aquecimento global?

Podemos notar a partir do coeficiente Eta (Figuras 3 e 4) que os itens 11 e 12 apresentam coeficientes de correlação tão elevados quanto as cargas fatoriais dos 10 itens (encontradas na Tabela 3). Isso permite utilizar os itens 11 e 12 para compor uma nova escala de opinião composta de doze itens. Ou seja, um novo Escore AGA obtido da média de 12 itens.

A concretização dessa possibilidade deve ser feita imputando às alternativas de cada item um escore. A forma de imputação adequada é aquela que determina que o coeficiente de correlação de Pearson entre a nova variável e o Escore AGA seja igual ao coeficiente Eta entre a variável nominal (alternativa de resposta ao item) e o Escore AGA. Conforme demonstrado por Wherry (1983), os valores imputados devem ser iguais às médias do Escore AGA em cada uma das alternativas de resposta nos dois itens. 
A Tabela 5 apresenta as alternativas nos itens 11 e 12 com os respectivos valores imputados de modo a se poder construir um novo Escore AGA baseado nas respostas a todos os 12 itens do opinário sobre aquecimento global antropogênico.

Tabela 5: Valores imputados às alternativas dos itens 12 e 13.

\begin{tabular}{|c|c|}
\hline $\begin{array}{l}\text { (a) O clima da Terra é muito estável; um aquecimento global terá pouco efeito sobre o } \\
\text { clima. }\end{array}$ & 1,3 \\
\hline $\begin{array}{l}\text { (b) O clima da Terra muda de forma lenta; um aquecimento global conduzirá a uma } \\
\text { mudança gradual do clima. }\end{array}$ & 5,4 \\
\hline $\begin{array}{l}\text { (c) O clima da Terra possui um equilibrio delicado; um pequeno aquecimento do planeta } \\
\text { pode levar a mudanças abruptas e catastroficas. }\end{array}$ & 8,6 \\
\hline $\begin{array}{l}\text { (d) O clima da Terra é estável dentro de certos limites; se o aquecimento for grande, efeitos } \\
\text { imprevisiveis e perigosos surgirão. }\end{array}$ & 7,9 \\
\hline \multicolumn{2}{|l|}{ 12. Qual das alternativas melhor descreve a pesquisa cientifica sobre aquecimento global? } \\
\hline $\begin{array}{l}\text { (a) E uma área de pesquisa complexa com muitas incertezas envolvidas, contudo, } \\
\text { cientistas já sabem que a atividade humana afeta o clima do planeta. }\end{array}$ & 8,5 \\
\hline $\begin{array}{l}\text { (b) É uma área de pesquisa complexa com muitas incertezas envolvidas; cientistas ainda } \\
\text { năo sabem se a atividade humana afeta ou não o clima do planeta. }\end{array}$ & 5,2 \\
\hline $\begin{array}{l}\text { (c) E uma área de pesquisa dominada por uma tendência a favor do aquecimento global; } \\
\text { cientistas com visões contrárias são frequentemente silenciados e impedidos de publicar } \\
\text { seus resultados. }\end{array}$ & 2,6 \\
\hline $\begin{array}{l}\text { (d) E uma área de pesquisa historicamente consolidada; é consenso entre cientistas que o } \\
\text { aquecimento global existe e que é causado pela atividade humana. }\end{array}$ & 9.2 \\
\hline
\end{tabular}

Feita a inclusão dos itens 11 e 12 como indicadores da opinião sobre o aquecimento global antropogênico, submeteu-se este conjunto de 12 variáveis a uma nova análise fatorial pelo método das componentes principais. A fatoração dos doze itens resultou novamente em que apenas a primeira componente possuía autovalor superior à unidade conforme representado no diagrama de sedimentação (scree plot) da Figura 5. 
Figura 5: Diagrama de sedimentação (scree plot) das componentes resultantes da fatoração dos doze itens.

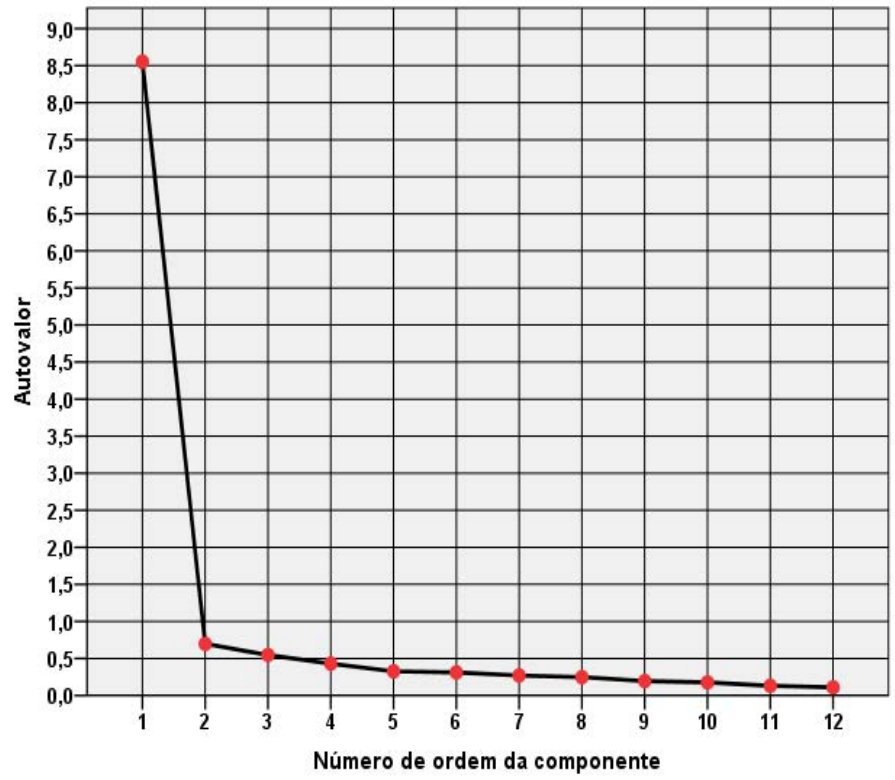

Desta forma, a análise fatorial dos doze itens corrobora outra vez com a existência de apenas um fator importante (com autovalor superior à unidade), explicando $71 \%$ da variância dos doze itens, verificando empiricamente a unidimensionalidade da opinião sobre o aquecimento global antropogênico nos doze itens. A partir do autovalor de uma componente, pode-se calcular o coeficiente alfa de Cronbach desta componente (MULAIK, 1972, p.211); neste caso, como o autovalor da primeira componente é 8,55, o coeficiente alfa resulta em 12/11 (1-1/8,55)=0,96.

A Tabela 6 apresenta a carga fatorial de cada item na primeira componente, configurando que todos os itens, por possuírem cargas positivas e superiores a 0,60, podem ser mantidos no opinário. Aqui, novamente, a carga fatorial é o coeficiente de correlação de Pearson entre o escore no item e o escore na componente principal. 
Tabela 6: Carga fatorial de cada item na primeira componente principal.

\begin{tabular}{|c|c|}
\hline Item & Carga \\
\hline 1 & $0,91^{*}$ \\
\hline 2 & $0,89^{\star}$ \\
\hline 3 & $0,83^{*}$ \\
\hline 4 & $0,87^{*}$ \\
\hline 5 & $0,87^{*}$ \\
\hline 6 & $0,83^{*}$ \\
\hline 7 & $0,67^{*}$ \\
\hline 8 & $0,83^{*}$ \\
\hline 9 & $0,92^{*}$ \\
\hline 10 & $0,92^{\star}$ \\
\hline 11 & $0,67^{\star}$ \\
\hline 12 & $0,87^{*}$ \\
\hline * - nível de significância estatística $<0,001$ \\
\hline
\end{tabular}

Com isso, podemos agora apresentar um novo histograma com o escore médio nos doze itens, ou seja, um novo Escore AGA para todos os respondentes expressando a opinião sobre o aquecimento global antropogênico (Figura 6).

Figura 6: Histograma do Escore AGA dos 12 itens para a amostra de 1084 sujeitos.

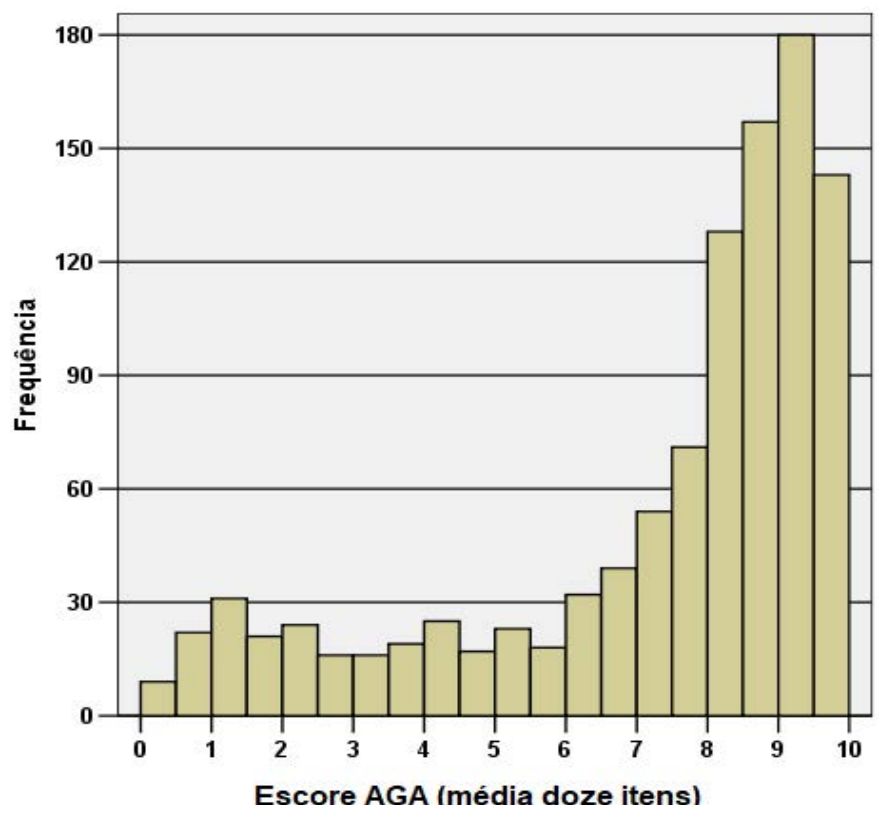


Para complementar a análise, a Tabela 7 apresenta diversas estatísticas do escore médio nos doze itens (novo Escore AGA).

Tabela 7: Estatísticas do Escore AGA obtido dos doze itens do opinário.

\begin{tabular}{|c|c|}
\hline \multicolumn{2}{|c|}{ Estatísticas do Escore AGA } \\
\hline Média & 7,3 \\
\hline Mediana & 8,4 \\
\hline Moda & 9,8 \\
\hline Desvio padrão & 2,6 \\
\hline Coeficiente alfa de Cronbach & 0,96 \\
\hline
\end{tabular}

O resultado da aplicação do instrumento de medida indica uma concordância majoritária da amostra de respondentes com a existência do aquecimento global antropogênico. Contudo, pode-se notar que existe um número considerável de respondentes, distribuídos ao longo de toda a escala de concordância/discordância, inclusive com um número não desprezível de respondentes com baixo Escore AGA, ou seja, discordando da existência de aquecimento global antropogênico.

Além disso, ao avaliar esse resultado, é importante não perder de vista as peculiaridades observadas em itens específicos do opinário, em especial, no que tange ao item sete (7) do opinário que afirma a existência de uma controvérsia científica sobre o aquecimento global antropogênico, ou seja, envolvendo a questão do consenso científico. Como indica a Figura 7, um número considerável de respondentes concorda com a afirmação feita no item 7 (escore menor que 5) e, portanto, considera que existe uma controvérsia científica em curso sobre o AGA. Este é um resultado que contrasta com o nível de consenso entre os especialistas mais ativos da área que vem sendo avaliado em trabalhos de revisão de literatura como estando acima de 95\% (ORESKES, 2004; ANDEREGG et al., 2010; DORAN; ZIMMERMAN, 2009; COOK et al., 2013). Ou seja, pode-se observar a existência de um distanciamento não desprezível entre a posição dos especialistas e a opinião da amostra de 1084 respondentes frente à questão do consenso científico sobre aquecimento global antropogênico. 
Figura 7: Histograma das respostas dos 1084 sujeitos para o item 7 do opinário (lembrando que no item 7 a gradação de 11 pontos foi invertida).

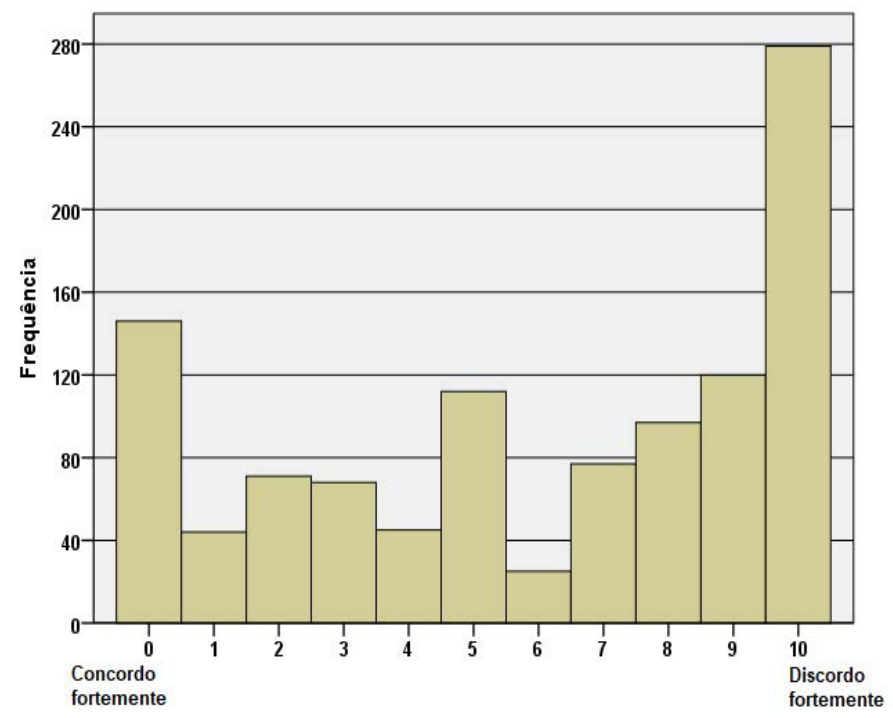

7. A existência de um aquecimento global causado pela ação humana ainda e matéria de ampla disputa na comunidade científica, não havendo consenso cientifico a respeito.

Por fim, podemos comentar os resultados obtidos com a análise dos itens 11 e 12 do opinário, ou seja, os dois itens de múltipla escolha apresentados nas Figuras 3 e 4. Com respeito ao item 11 (Figura 3), pode-se notar que o grupo de respondentes que considera que o clima da Terra é muito estável (imune aos efeitos do aquecimento global), apresenta Escore AGA baixo, indicando uma forte discordância com a origem antropogênica do aquecimento global. Por sua vez, o grupo de respondentes que considera que o clima é pouco estável (equilíbrio sensível e delicado) exibe o maior Escore AGA. Cabe notar ainda que, entre as alternativas da questão 11, aquela que configura a posição científica mais aceita é a que afirma que "O clima da Terra é estável dentro de certos limites; se o aquecimento for grande, efeitos imprevisíveis e perigosos surgirão" (LEISEROWITZ; SMITH, 2010, p.71).

Quanto ao item 12 (Figura 4), podemos observar que o grupo de respondentes com mais baixo Escore AGA tem a percepção de que é uma área de pesquisa científica dominada por uma ortodoxia dogmática que silencia as vozes dos cientistas céticos. Por sua vez, o nível mais elevando do Escore AGA acontece no grupo de respondentes que percebe a área climática como sendo uma área de pesquisa his- 
toricamente consolidada. Novamente, a literatura indica que entre as alternativas, as duas opções mais razoáveis são as que reconhecem a ação humana influenciando o clima (FLEMING, 1998; WEART, 2008; IPCC, 2013).

\section{Caracterização da amostra de respondentes}

A caracterização da amostra de 1084 respondentes é feita a partir da análise da primeira parte do opinário que trata das informações básicas dos respondentes, incluindo variáveis como: idade, sexo, nacionalidade, unidade da federação onde mora, grau de escolaridade, área de formação, nível de informação sobre o tema e as fontes de informação mais consultadas. Apresentamos os resultados das respostas dos 1084 sujeitos na forma de gráficos de barra com as distribuições de frequência para cada uma das variáveis. Cabe, novamente, observar que os resultados da amostra não permitem generalizações para população em geral, uma vez que o opinário foi disponibilizado online em blogs e redes sociais frequentados por, possivelmente, um público específico interessado por questões científicas.

A idade dos respondentes, originalmente indicada como o número de anos completos de vida, está agrupada em sete intervalos de classe, cada um deles perfazendo um total de cerca de $14 \%$ dos 1084 respondentes (Figura 8). A idade mínima foi de 12 anos e a máxima de 81 anos, sendo a média 33,5 anos e o desvio padrão de 14,4 anos. Com respeito à variável sexo (Figura 8 ), a maioria dos respondentes $(78,7 \%$ ) são do sexo masculino, sendo que apenas três sujeitos classificaram-se na categoria outro. Chama a atenção o baixo número de respondentes femininas (em torno de $21 \%$ do total). Isso pode estar mostrando que, entre o público de não especialistas, também não há paridade de gênero com respeito ao interesse por temas científicos, da mesma forma que ocorre entre os praticantes da ciência. ${ }^{5}$ 
Figura 8: Gráficos de distribuição de frequências para as categorias de idade e sexo.
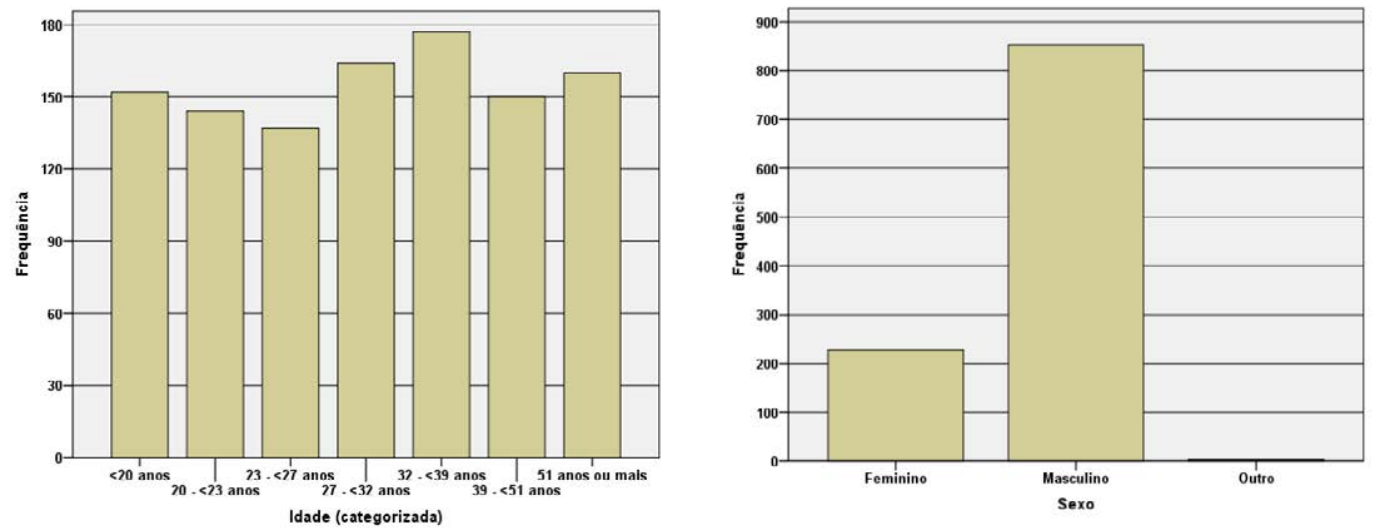

Quanto à variável nacionalidade, a quase totalidade dos respondentes são de nacionalidade brasileira (98,2\%), sendo apenas $1,8 \%$ estrangeiros, dessa forma, este resultado não está apresentado na forma de gráfico de barras. Os locais de residência dos respondentes abrangem todas as unidades da federação conforme se observa gráfico da Figura 9, sendo a maioria do Rio Grande do Sul (41,7\%) e São Paulo (17\%), ocorrendo $2,7 \%$ de residentes no exterior.

Figura 9: Gráfico de distribuição de frequências para os locais de residência dos respondentes.

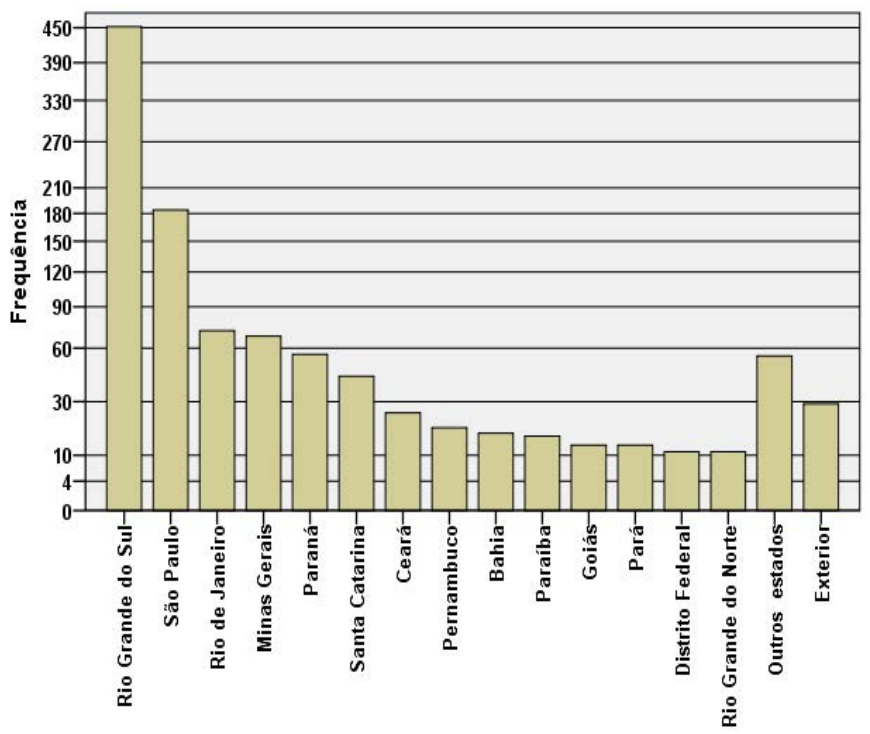

Residência 
O grau mais elevado de escolaridade informado pelos respondentes começa com o ensino médio ou menor e vai até o doutorado conforme indica a Figura 10. Pode-se notar que mais da metade dos respondentes possui graduação completa.

Figura 10: Gráfico de distribuição de frequências para o maior grau de escolaridade dos respondentes.

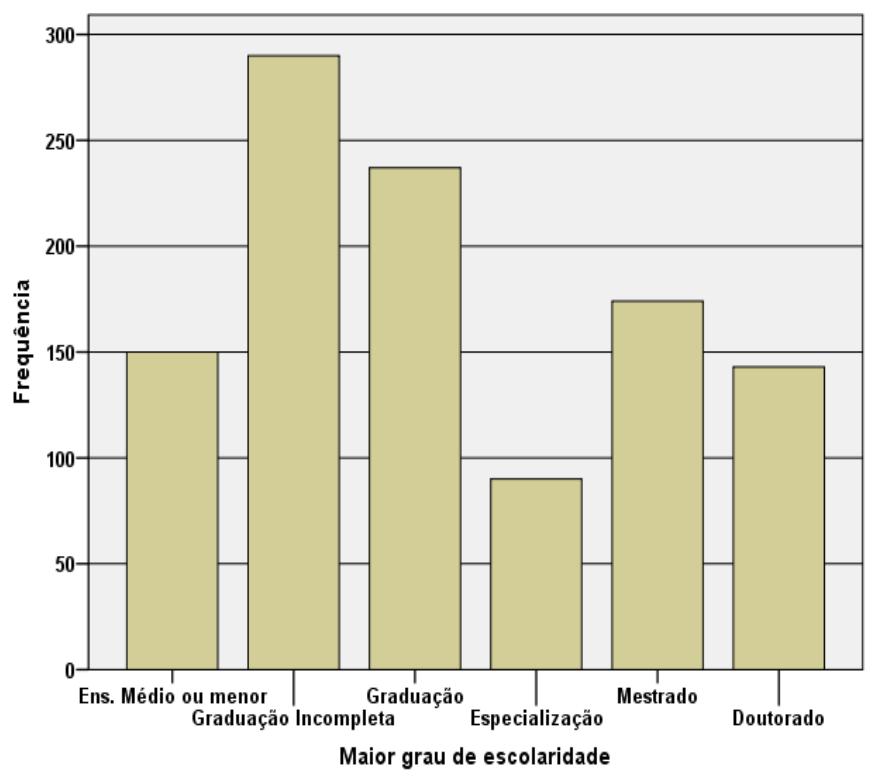

A área de formação superior (graduação) dos respondentes abrange nove categorias conforme indica a Figura 11. Pode-se observar que a área de formação Ciências exatas e da Terra exibe o maior número de respondentes. Como já observado, este resultado possivelmente deve-se ao fato do opinário ter sido divulgado online em blogs e redes sociais frequentados por um público interessado pelas questões científicas. 
Figura 11: Gráfico de distribuição de frequências da área de formação dos respondentes.

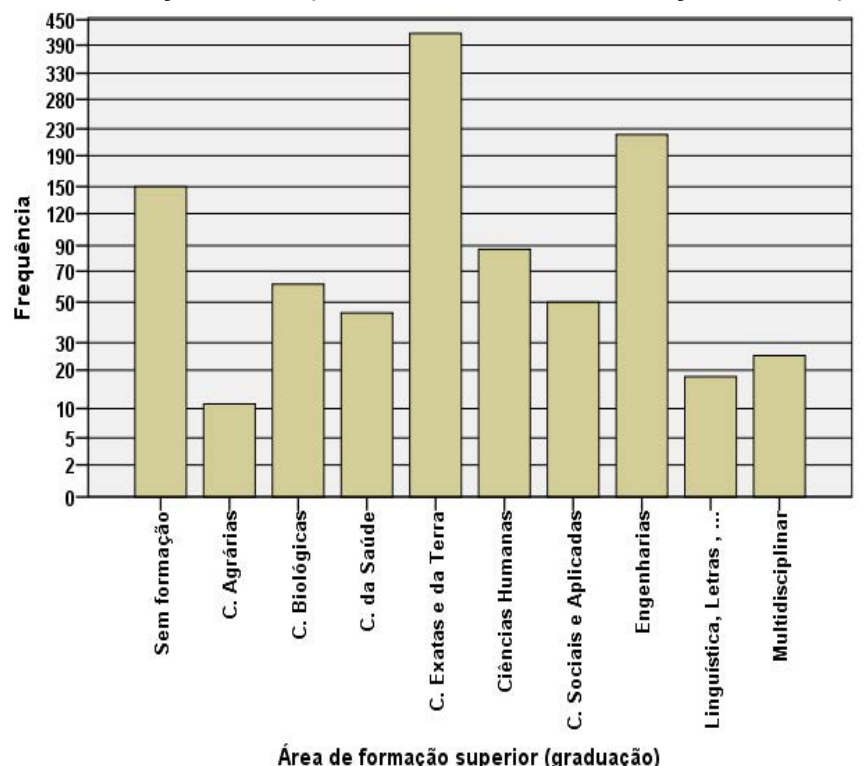

Quanto à variável Nível de informação sobre o tema, apenas 17\% dos respondentes se considera pouco ou nada informado sobre o tema do aquecimento global, conforme indica a Figura 12. A ampla maioria dos respondentes considera-se informada sobre o tema.

Figura 12: Gráfico de distribuição de frequências para a opinião dos respondentes sobre seus conhecimentos relativos ao aquecimento global.

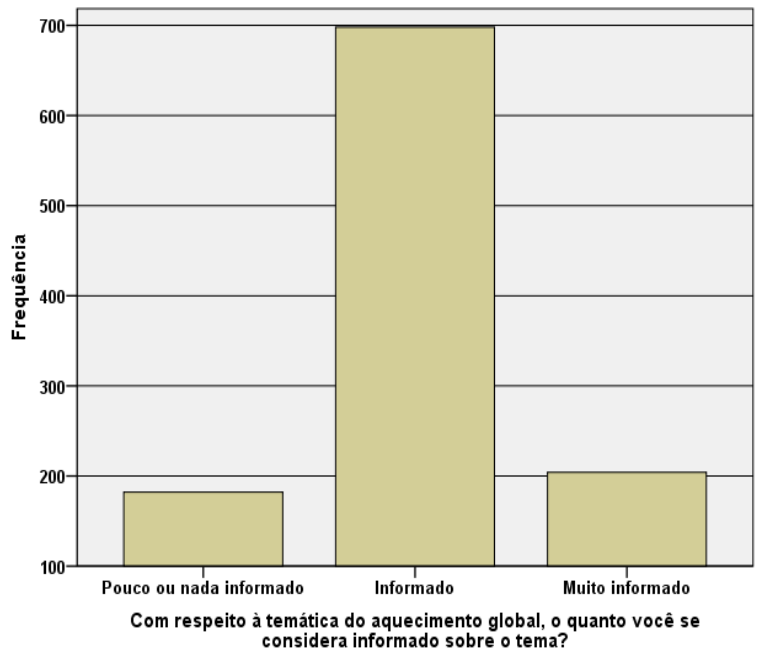


Considerando as fontes de informação consultadas: Internet (youtube, blogs e redes sociais); Televisão, Rádio e Jornais; Websites do Governo e Centros de Pesquisa (Nasa, Inpe, etc.); Livros e / ou Revistas Científicas; Escola e / ou Universidade, verifica-se que a Internet (youtube, blogs e redes sociais) é a mais utilizada, constituindo a principal fonte de informação sobre o tema do aquecimento global (Figura 13 e Figura 14). Pode-se, também, observar uma considerável homogeneidade nas frequências de consultas às fontes de informação como Televisão, Rádio e Jornais; Websites do Governo e Centros de Pesquisa (Nasa, Inpe, etc); Livros e/ou Revistas Científicas.

Figura 13: Gráficos de distribuição de frequências sobre a intensidade com a qual a internet e os meios de comunicação (televisão, rádio, jornais) aparecem como informativos sobre o tema do aquecimento global.
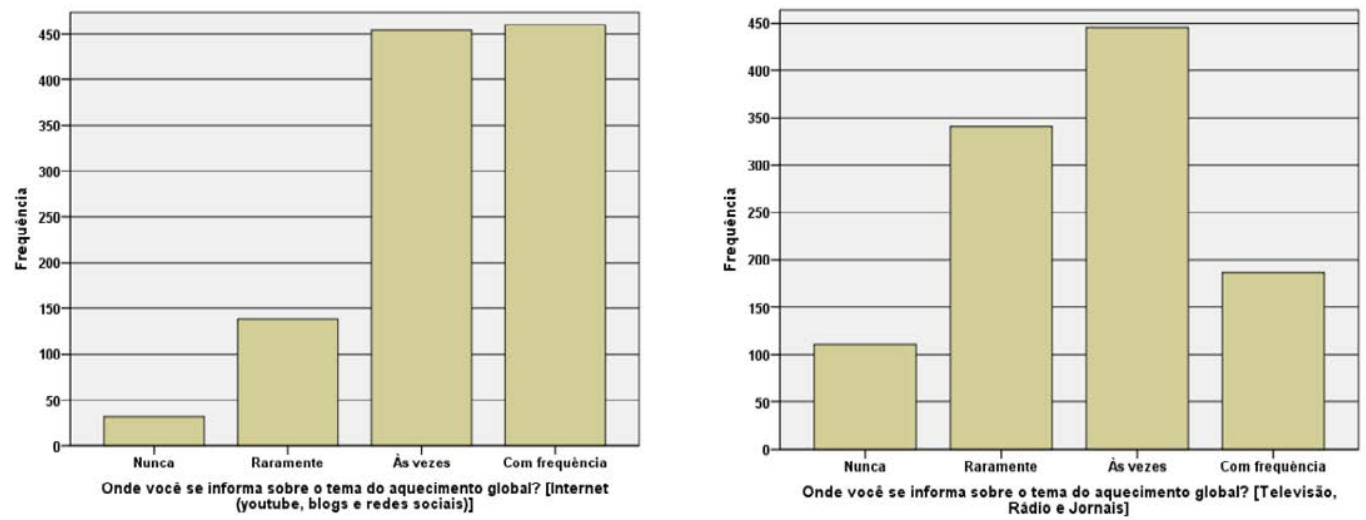

Figura 14: Gráficos de distribuição de frequências sobre a intensidade com a qual a literatura e sites oficiais informam sobre o tema do aquecimento global.
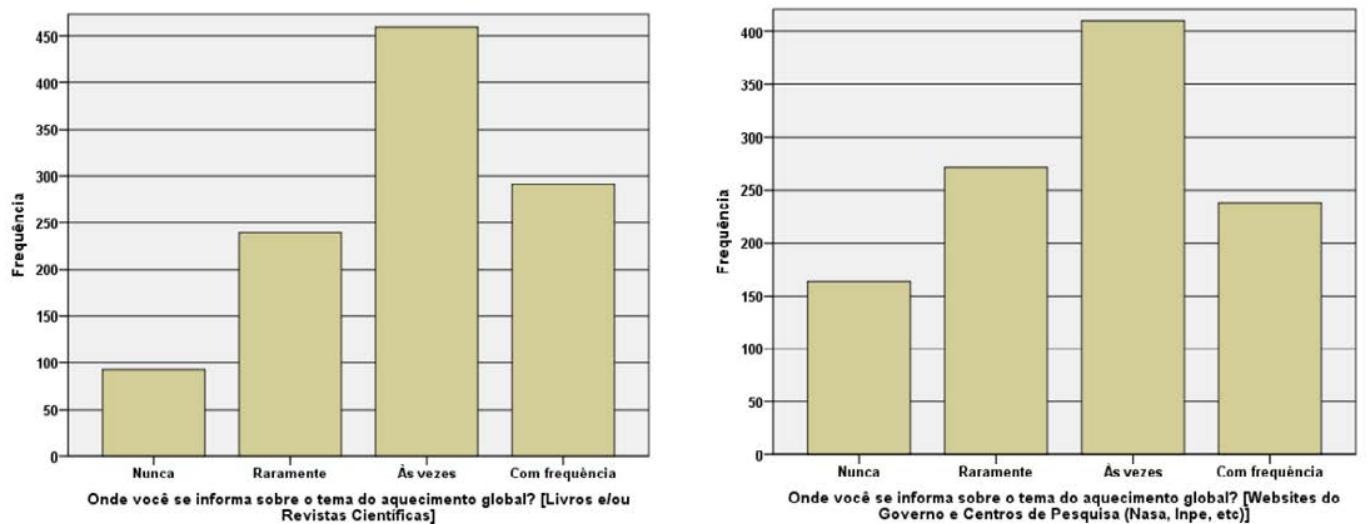
Por sua vez, no que tange ao papel da educação formal como fonte de informação, pode-se assinalar que um número considerável de respondentes avalia que nunca ou raramente se informa ou é informado sobre o tema do aquecimento global através deste meio. Ou seja, a Escola e/ou Universidade parecem ter um protagonismo tímido segundo esses respondentes (Figura 15).

Figura 15: Gráficos de distribuição de frequências sobre a intensidade com a qual os respondentes reconhecem a educação formal informando sobre o aquecimento global.

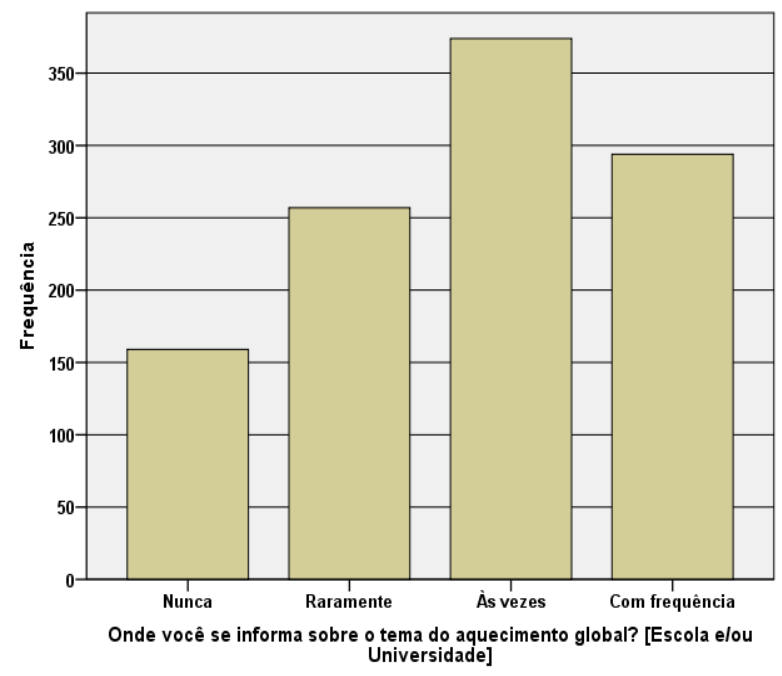

\section{Correlação entre as variáveis de caracterização dos respondentes com o Escore AGA}

Passaremos agora a discutir a correlação entre as variáveis de caracterização dos respondentes e o Escore AGA obtido com os doze itens da escala de opinião sobre aquecimento global. Como já assinalado, a forma de analisar se uma variável nominal (por exemplo, uma variável que expressa uma característica qualitativa do respondente) possui relação com o Escore AGA é pelo cálculo do coeficiente Eta entre a variável e o Escore AGA. Além do coeficiente Eta, o cálculo do coeficiente Eta ao quadrado fornece um indicativo do tamanho do efeito. Ou seja, o quadrado de Eta expressa a proporção da variância do Escore AGA explicada pela respectiva variável de caracterização.

Lembremos que, entre as variáveis de caracterização dos respondentes, estão as informações básica dos sujeitos como idade, sexo, grau de escolaridade, etc. A 
análise indicou que nenhuma das variáveis de caracterização dos respondentes apresentou um coeficiente Eta superior a 0,22. O quadrado de Eta, que expressa a proporção da variância do Escore AGA explicada pela respectiva variável de caracterização, resultou em um valor máximo de 0,048 $\left(0,22^{2}=0,048\right)$. Desta forma, a máxima variância explicada foi de cerca de $5 \%$, ou seja, qualquer uma das variáveis apresentou baixo poder explicativo sobre o Escore AGA.

Apesar do baixo valor para o coeficiente Eta, é relevante comparar as diferentes médias no Escore AGA entre os grupos compostos por cada uma das categorias das variáveis de caracterização que apresentou correlação estatisticamente significativa com o Escore AGA, ou seja, valores de significância estatística menores que 0,05 $(\mathrm{ns}<0,05)$. Para tanto, a seguir, são apresentados os gráficos de barra de erro (a barra de erro representa um desvio padrão da média) para as variáveis com correlação estatisticamente significativa. Como pode ser observado, junto aos gráficos, é apresentado o coeficiente Eta e o seu nível de significância estatística (ns).

Alguns resultados obtidos merecem destaque. Como indicam os gráficos de barra de erro da Figura 16, respondentes mais jovens tendem a apresentar maior Escore AGA do que respondentes acima de 32 anos, enquanto que o grupo de respondentes femininos apresenta, em média, maior Escore AGA do que respondentes do sexo masculino. A este respeito Christensen e Knezek (2015) apontam estudos que indicam que o público feminino, além de possuir atitudes mais positivas frente ao meio ambiente, demonstram estar mais preocupados com o meio ambiente do que o público masculino.

Figura 16: Gráficos de barra de erro para o Escore AGA nas categorias de idade e sexo dos respondentes.
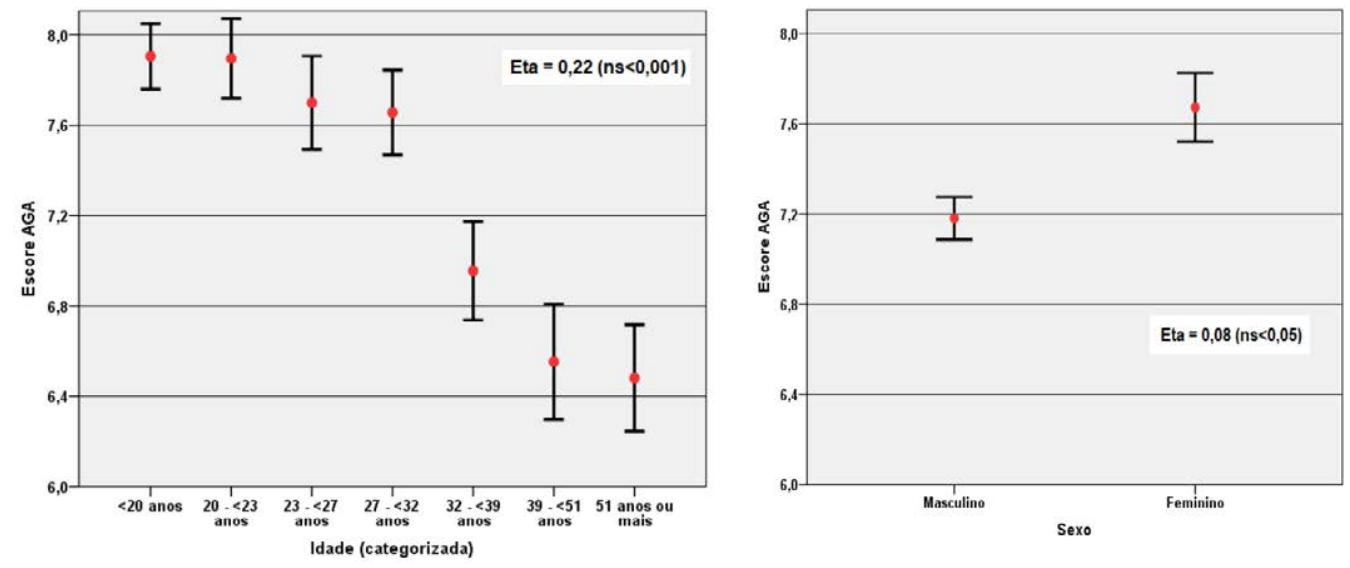
Dentre as categorias de escolaridade, o grupo de respondentes com Doutorado apresenta Escore AGA ligeiramente maior que os demais (Figura 17). É interessante notar que, entre as categorias que expressam o grau de informação sobre o tema, aqueles que se declaram os mais informados sobre o tema expressam o menor Escore AGA (Figura 17).

Figura 17: Gráficos de barra de erro para o Escore AGA nas categorias da escolaridade do respondente e grau de informação sobre o tema do aquecimento global.
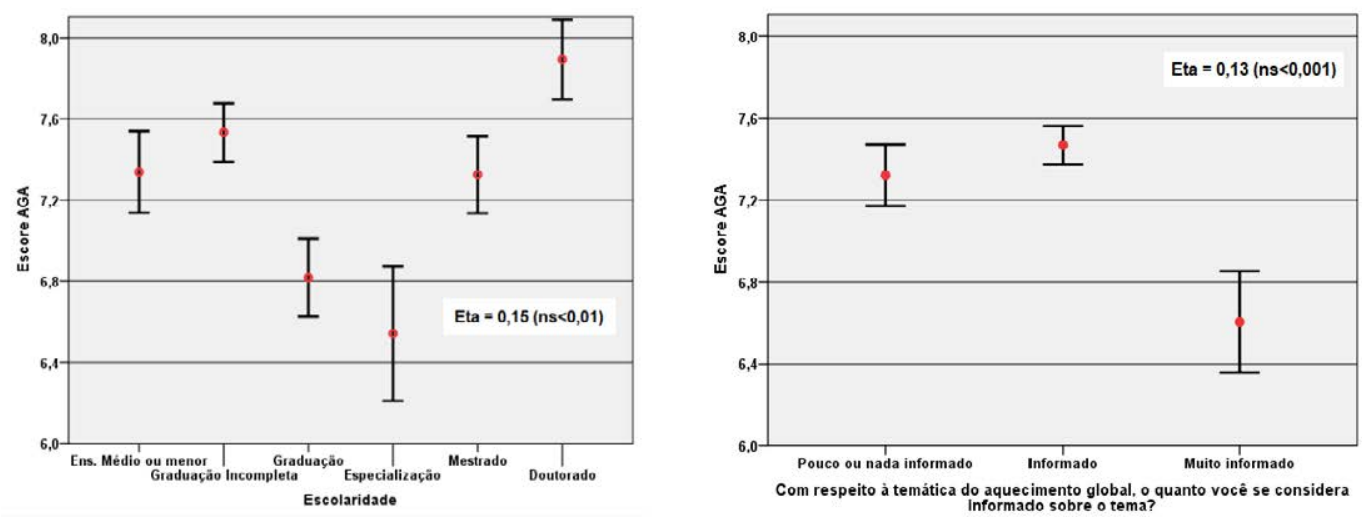

As figuras 18 e 19 apresentam os resultados com respeito ao tipo de fonte de consulta dos respondentes. Podemos ver que o grupo de respondentes que consulta com mais frequência a internet para se informar sobre o tema, apresenta o menor Escore AGA (Figura 18). O grupo de respondentes que se informa sobre o tema com maior frequência na Escola e/ou Universidade possui Escore AGA ligeiramente maior do que as demais categorias (Figura 19). 
Figura 18: Gráficos de barra de erro para o Escore AGA na categoria frequência de consulta sobre o tema do aquecimento global na internet (youtube, blogs e redes sociais) e na televisão, rádio e jornal.
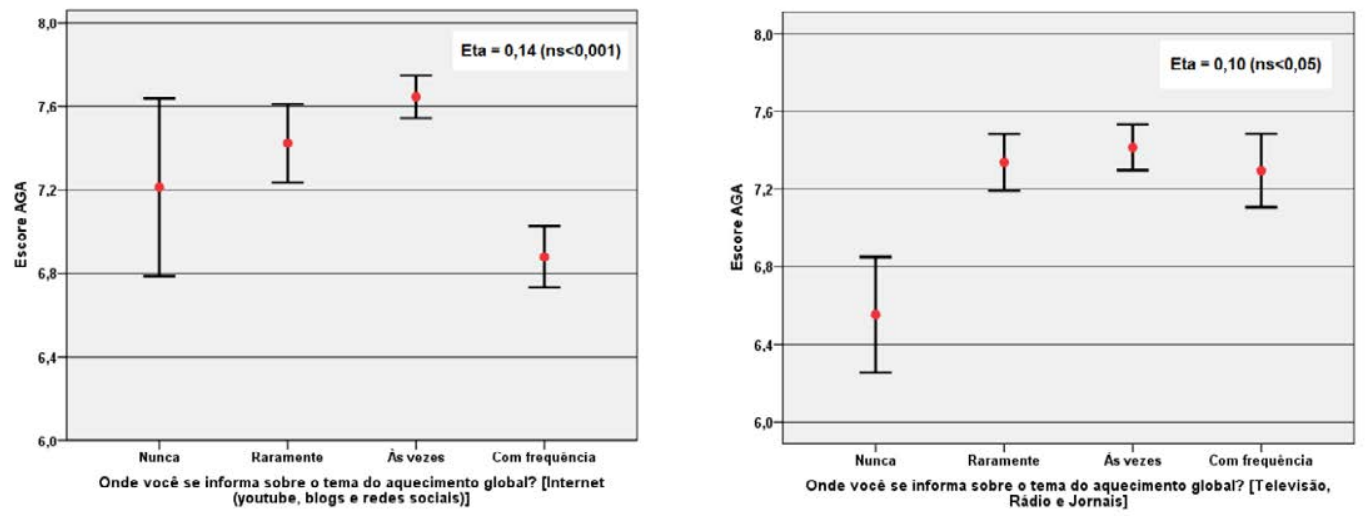

Figura 19: Gráficos de barra de erro para o Escore AGA na categoria frequência de consulta sobre o tema do aquecimento global em livros e/ou revistas científicas e na escola e/ou universidade.
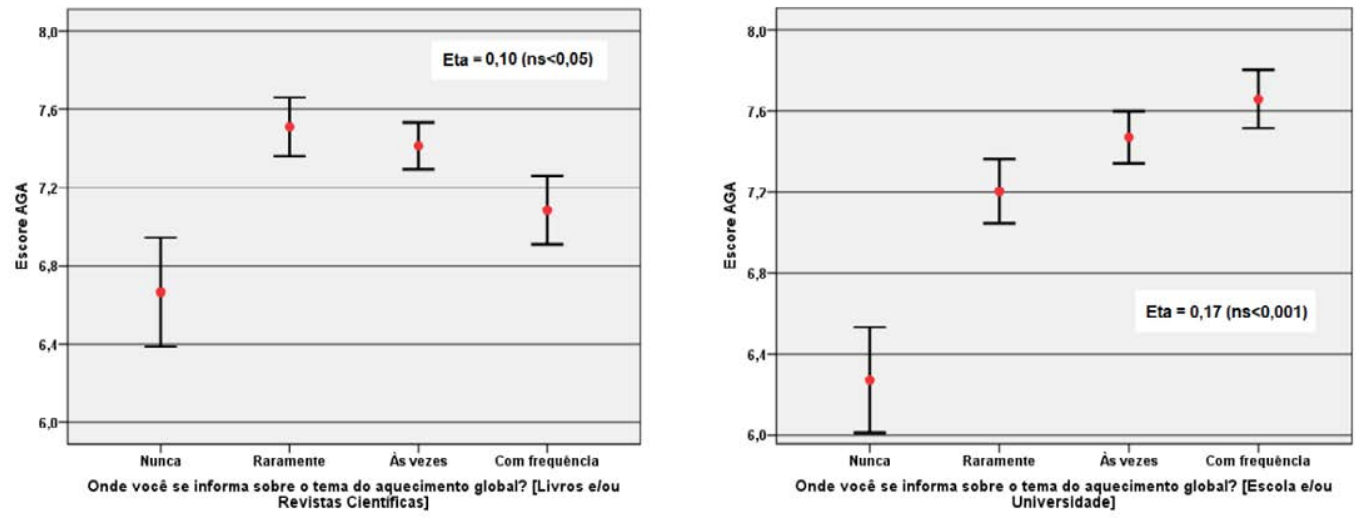

\section{Considerações finais}

Tendo em vista a relevância atual da temática do aquecimento global e, a exemplo de pesquisas com opinários sobre o tema no contexto internacional, este trabalho pretendeu contribuir para o desenvolvimento de pesquisas similares no contexto brasileiro local. Para tanto, foi apresentada a análise das respostas de uma amostra de 1084 sujeitos a um opinário sobre aquecimento global, cujo construto 
principal diz respeito à existência do Aquecimento Global Antropogênico (AGA). Como já observado, a amostra casual de 1084 sujeitos não constitui uma amostra representativa da população brasileira, de modo que os resultados obtidos no estudo de correlação entre as variáveis de caracterização da amostra e o Escore AGA limitam-se apenas a essa amostra específica.

No que tange a pergunta sobre o grau de concordância ou discordância frente ao AGA, os resultados da aplicação do instrumento de medida indicam que existe uma concordância majoritária entre os respondentes sobre a realidade do aquecimento global antropogênico (Escore AGA). Contudo, com relação à existência de uma controvérsia científica (item 7 - Figura 19), um número considerável de respondentes considera que existe uma controvérsia científica em curso a respeito do tema, indicando um distanciamento não desprezível entre a opinião da amostra de respondentes e a posição dos especialistas.

O resultado da análise das correlações entre as variáveis nominais e o Escore AGA indica que respondentes mais jovens tendem a apresentar Escore AGA maior do que respondentes acima de 32 anos e respondentes femininos apresentam maior Escore AGA do que respondentes do sexo masculino. Nas categorias de escolaridade, o grupo de respondentes com maior grau de escolaridade (Doutorado) apresenta o maior Escore AGA. Curiosamente, aqueles que se declaram os mais informados sobre o tema expressam o menor Escore AGA, resultado que conflita com a evidência de consenso sobre o aquecimento global antropogênico entre especialistas. Por sua vez, o grupo de respondentes que consulta com mais frequência a internet para se informar sobre o tema expressa o menor Escore AGA, enquanto que o grupo de respondentes que recorre com mais frequência à Escola e / ou Universidade expressa um grau de concordância maior sobre o AGA.

Embora uma investigação mais aprofundada fosse necessária para avaliar se tais correlações entre variáveis seriam confirmadas em estudos com outras amostras, cabe notar que a grande variância das respostas indica que se trata de um tema ainda pouco compreendido. De fato, diversos autores da área de ensino de ciências têm chamado a atenção para a necessidade de uma maior inserção e discussão da temática do aquecimento global no contexto da educação formal, seja no que tange ao conteúdo científico envolvido, quanto aos aspectos epistemológicos, como a natureza das controvérsias científicas (SHARMA, 2012; KOLSTO, 2001). Como é bem sabido, a disponibilidade e acesso à informação, por si só, não se constitui 
em condição suficiente para a aquisição de novos conhecimentos, sendo papel da educação formar cidadãos munidos de competências e habilidades para interpretar informações em situações relacionadas a tópicos científicos e sociocientíficos complexos como é o caso do aquecimento global.

Por fim, como principal contribuição do presente trabalho à área de pesquisa em ensino de ciências, destacamos o processo de validação de conteúdo e de construto do opinário. Através da análise de consistência interna dos doze itens do opinário foi possível realizar a validade de construto, demonstrando que o opinário constitui um instrumento de medida apropriado para avaliar a concordância ou discordância do respondente quanto ao construto AGA, obtendo-se um coeficiente alfa de Cronbach de 0,96.

Dessa forma, consideramos que o opinário poderá ser empregado por professores em sala de aula e adaptado por outros pesquisadores em pesquisas futuras para averiguar a opinião de determinados grupos de respondentes sobre o tema. Além disso, pode-se também vislumbrar reformulações do opinário com diferentes combinações de questões. Por exemplo, empregando apenas a escala composta de dez itens do tipo Likert (Tabela 1), especialmente, quando o interesse é averiguar o posicionamento de respondentes frente ao aquecimento global antropogênico.

\section{Validation of an Opinary on Global Warming}

\section{Abstract}

Global warming has been recognized by experts as a primary topic of environmental education for the 21 st century. Scientists have warned humanity about the urgency of climate change caused by anthropogenic greenhouse gases. Despite this, the perception on the theme among the lay people is diffuse. In the international context, studies have revealed that a considerable number of lay people do not believe in anthropogenic global warming or consider that there is no scientific consensus on the subject. Therefore, in view of the importance of the subject and the differences of opinion between lay people and experts in international contexts, it is relevant to develop similar research in the local Brazilian context. This paper describes the development of an instrument to assess citizens and students opinion on global warming in the Brazilian context. So, we describe the steps of development, application and validation of an opinary on global warming. The opinary, composed of twelve items, was made available online on social networks and mailing lists using the software LimeSurvey, obtaining a total of 1084 responses. We describe the process of questionnaire validation and conclude that it constitutes an appropriate instrument to measure the degree of agreement or disagreement of subjects on the construct "anthropogenic global warming". Finally, possible correlations between the subjects' characterization variables and the belief in global warming are discussed.

Keywords: global warming; climate change; survey research; questionnaire validation. 


\section{Referências}

ANDEREGG, W.; PRALL, J.; HAROLD, J.; SCHNEIDER, S. Expert credibility in climate change. Proceedings of The National Academy of Sciences, v.107, n.27, p.12107-12109, 2010. Disponível em: http://dx.doi.org/10.1073/pnas.1003187107. Acesso em: 10 jan. 2020.

ARSLAN, H.; CIGDEMOGLU, C.; MOSELEY, C. A three-tier diagnostic test to assess pre-service teachers misconceptions about global warming, greenhouse effect, ozone layer depletion, and acid rain. International Journal of Science Education, v.34, n11, p. 1667-1686, 2012. Disponível em: https://doi.org/10.1080/09500693.2012.680618. Acesso em: 10 jan. 2020.

BARRY, Roger; CHORLEY, Richard. Atmosfera, tempo e clima. Porto Alegre: Bookman, 2013.

CHRISTENSEN, R.; KNEZEK, G. The climate change attitude survey: measuring middle school student beliefs and intentions to enact positive environmental change. International Journal of Environmental \& Science Education, v.10, n.5, p.773-788, 2015. Disponível em: http:// www.ijese.net/makale_indir/ijese.2015.276a.pdf. Acesso em: 10 maio 2020.

CHRISTOPHERSON, Robert. Geossistemas: uma introdução a geografia física. Porto Alegre: Bookman, 2012.

COOK, J.; NUCCITELLI, D.; GREEN, S. A.; RICHARDSON, M.; WINKLER, B.; PAINTING, R.; WAY, R.; JACOBS, P.; SKUCE, A. Quantifying the consensus on anthropogenic global warming in the scientific literature. Environmental Research Letters, v.8, n.2, p.1-7, 2013. Disponível em: http://dx.doi.org/10.1088/1748-9326/8/2/024024. Acesso em: 10 jan. 2020.

DAWSON, V. Western Australian high school students' understanding about the socioscientific issue of climate change. International Journal of Science Education, v.37, n.7, p. 1024-1043, 2015. Disponível em: https://doi.org/10.1080/09500693.2015.1015181. Acesso em: 20 mar. 2020.

DORAN, P.; ZIMMERMAN, M. Examining the Scientific Consensus on Climate Change. Eos, Transactions American Geophysical Union, v.90, n.3, p.22-23, 2009. Disponível em: http:// dx.doi.org/10.1029/2009eo030002. Acesso em: 10 jan. 2020.

DRIVER, R. Students' conceptions and the learning of science. International Journal of Science Education. v.11 (Especial issue), p.481-490, 1989. Disponível em: https://doi. org/10.1080/0950069890110501. Acesso em: 5 abr. 2020.

FLEMING, James. Historical Perspectives on Climate Change. New York: Oxford University Press, 1998.

GOODY, R.; WALKER, James. Atmosferas planetárias. São Paulo: Edgard Blucher, 1996.

GUREL, D.K.; ERYILMAZ, A.; McDERMOTT, L.C. A review and comparison of diagnostic instruments to identify studenys' misconceptions in science. Eurasia Journal of Mathematics, Science \& Technology Education, v.11, n.5, p.989-1008, 2015. Disponível em: https://oi. org/10.12973/eurasia.2015.1369a. Acesso em: 15 maio 2020.

HERMAN, B.; FELDMAN, A.; VERNAZA-HERNANDEZ, V. Florida and Puerto Rico Secondary Science Teachers' Knowledge and Teaching of Climate Change Science. International Journal of Science and Mathematics Education. v.15, n.3, p. 451-471, 2017. Disponível em: https:// doi.org/10.1007/s10763-015-9706-6. Acesso em: 10 jan. 2020. 
IALEI - International Alliance of Leading Education Institutes. Climate Change and Sustainable Development: The Response from Education: a cross-national report from International Alliance of Leading Education Institutes. Denmark: IALEI, 2009. Disponível em: http://rce-denmark.dk/sites/default/files/2017-04/Climatechangeandeducation.pdf. Acesso em: 5 mar. 2020.

IPCC. Summary for Policymakers. In: STOCKER,T.; QIN, D.; PLATTNER, G.; TIGNOR, M.; ALLEN, S.; BOSCHUNG, J.; NAUELS, A.; XIA, Y.; BEX, V.; MIDGLEY, M. (Eds.). Climate Change 2013: The Physical Science Basis. Cambridge: Cambridge University Press, 2013. Disponível em: https://www.ipcc.ch/site/assets/uploads/2018/02/WG1AR5_SPM_FINAL.pdf. Acesso em: 5 mar. 2020.

JACOBI, P. R.; GUERRA, A. F.; SULAIMAN, S. N.; NEPOMUCENO, T. Mudanças climáticas globais: a resposta da educação. Revista Brasileira de Educação, Rio de Janeiro, v. 16, n. 46, p. 135-148, 2011. Disponível em: http://www.scielo.br/pdf/rbedu/v16n46/v16n46a08.pdf. Acesso em: 15 mar. 2020.

KOLSTO, S. Scientific Literacy for Citizenship: tools for dealing with the science dimension of controversial socioscientific issues. Science Education, v.85, n.3, p. 291-310, 2001. Disponível em: https://doi.org/10.1002/sce.1011. Acesso em: 8 abr. 2020.

LAMBERT, J.; LINDGREN, J.; BLEICHER, R. Assessing elementary science methods students' understanding about global climate change. International Journal of Science Education, v. 34, n. 8, 1167-1187, 2012. Disponível em: https://doi.org/10.1080/09500693.2011.633938. Acesso em: 10 fev. 2020.

LEISEROWITZ, A.; SMITH, N. Knowledge of Climate Change Across Global Warming's Six Americas. Yale University. New Haven, CT: Yale Project on Climate Change Communication, 2010. Disponível em: http://environment.yale.edu/climate-communication-OFF/files/Knowledge_Across_Six_Americas.pdf. Acesso em Março de 2020. Acesso em: 5 fev. 2020.

LIKERT, R. Una tecnica para medir actitudes. In: SUMMERS, G. F (org.). Medición de actitudes. Mexico: Trillas, 1986.

LOMBARDI, D.; SINATRA, G. Emotions about teaching bout human-induced climate change. International Journal of Science Education, v.35, n.1, p. 167-191, 2013. Disponível em: https://doi.org/10.1080/09500693.2012.738372. Acesso em: 10 mar. 2020.

LOMBARDI, D.; SINATRA, G. College Students' perceptions about the plausibility of human induced climate change. Research in Science Education, v.42, n.2, p.201-217, 2012. Disponível em: https://link.springer.com/article/10.1007/s11165-010-9196-z. Acesso em: 5 mar. 2020.

LOMBARDI, D.; SINATRA, G.; NUSSBAUM, M. Plausibility reappraisals and shifts in middle school students' climate change conceptions. Learning and Instruction, v.27, p. 50-62, 2013. Disponível em: https://doi.org/10.1016/j.learninstruc.2013.03.001. Acesso em: 5 mar. 2020.

MOREIRA, Marco Antônio. Teorias da aprendizagem. São Paulo: Editora Epu, 2011.

MULAIK, Stanley. The foundations of factor analysis. New York: McGraw-Hill, 1972.

NIBERT, K.; GROPENGIESSER, H. Understanding the greenhouse effect by embodiment Analysing and using students' and scientists' conceptual resources. International Journal of Science Education, v.36, n.2, p. 277-303, 2014. Disponível em: https://doi.org/10.1080/095006 93.2013.763298. Acesso em: 20 mar. 2020. 
ORESKES, N. Beyond the ivory tower: The Scientific Consensus on Climate Change. Science, v.306, n.5702, p. 1686-1686, 2004. Disponível em: http://dx.doi.org/10.1126/science.1103618. Acesso em: 15 jan. 2020.

PASQUALI, Luiz. Psicometria: teoria dos testes na psicologia e na educação. Petrópolis: Editora Vozes, 2013

PLUTZER, E.; McCAFFEY, M.; HANNAH, L.; ROSENAU, J.; BERBECO, M.; REID, A. Climate confusion among U.S. teachers: teachers' knowledge and values can hinder climate education. Science Education, v.351, n.6274, p. 664-665, 2016. Disponível em: https://doi.org/10.1126/ science.aab3907. Acesso em: 5 maio 2020.

RATINEN, I. Primary student-teachers' conceptual understanding of the greenhouse effect: a mixed method study. International Journal of Science Education, v.35, n.6, p. 929-955, 2013. Disponível em: https://doi.org/10.1080/09500693.2011.587845. Acesso em: 25 fev. 2020.

REINFRIED, S.; TEMPELMANN, S. The impact of secondary school students' preconceptions of the evolution of their mental models of the greenhouse effect and global warming. International Journal of Science Education, v.36, n.2, p. 304-333, 2014. Disponível em: https://doi.org/10. 1080/09500693.2013.773598. Acesso em: 25 mar. 2020.

SHARMA, A. Global climate change: what as science education got to do with it? Science \& Education, v. 21, n. 1, p. 33-53, 2012. Disponível em: https://doi.org/10.1007/s11191-011-9372-1. Acesso em: 15 abr. 2020.

SCHIEBINGER, L. Mais mulheres na ciência: questões de conhecimento. História, Ciências, Saúde-Manguinhos, v.15(suplemento), p. 269-281, 2008. Disponível em: http://dx.doi.org/10.1590/ S0104-59702008000500015. Acesso em: 10 maio 2020.

SPEARRITT, D. Factor analysis. In: KEEVES, J. P. (org.). Educational research, methodology, and measurement: an international handbook. Cambridge: Pergamon, 1997.

WEART, Spencer. The discovery of global warming. Cambridge, Massachusetts: Harvard University Press., 2008.

WHERRY, Robert. Contributions to correlational analysis. Orlando: Academic Press, 1984. 